\title{
Reviving Mortgage Securitization: Lessons from the Brady Plan and Duration Analysis
}

\author{
Fabià Gumbau-Brisa and Catherine L. Mann
}

\begin{abstract}
:
We review the period of the Latin American debt crisis in order to draw policy analogies from that experience for current U.S. credit securitization markets. During the earlier episode the Brady Plan used a zero-coupon U.S. Treasury security to provide a credit enhancement for the troubled assets. This revitalized the market for Latin American debt by: (1) ameliorating the dual solvency problem that affected both creditors and debtors, and (2) revealing asset prices as dominated by risk fundamentals rather than by short-run factors. The cost of the Brady plan was quite small relative to its social benefits. To address today's problems in some U.S. securitization markets, we argue that U.S. policymakers could implement a related form of cash flow enhancement with the potential for achieving similar outcomes. Analyzing the Brady bond credit enhancement as applied to a class of today's mortgage securities reveals that the optimal timing for the credit enhancement targets cash-flows that are somewhat distant from the present and its financial turmoil. An additional benefit of this, in both the Brady Bond case and under our proposal, is that the probability of the program sponsor needing to make payments associated with the enhancement is likely to be lower if the intervention is indeed effective. Hence, refining the timing of the suggested enhancements has two mutually-reinforcing beneficial effects; through this program, an optimally designed large-scale commitment can have a lower final cost for the tax-payer than a smaller one that is more likely to fail.
\end{abstract}

JEL Classifications: D82, E44, F34, G01, G21

Fabià Gumbau-Brisa is a senior economist at the Federal Reserve Bank of Boston. Catherine L. Mann is a professor of economics at Brandeis University, a senior fellow at the Peterson Institute for International Economics, and a visiting scholar at the Federal Reserve Bank of Boston. Their e-mail addresses are Fabia.Gumbau-Brisa@bos.frb.org and CLMann@Brandeis.edu, respectively. We appreciate David Kotok and Blake LeBaron reading early versions of the paper.

This paper, which may be revised, is available on the web site of the Federal Reserve Bank of Boston at http://www.bos.frb.org/economic/ppdp/index.htm.

The views expressed in this paper are solely those of the authors and do not necessarily represent those of the Federal Reserve Bank of Boston or the Federal Reserve System.

Date: original version April, 2009; this version, June 30, 2009 


\section{Introduction}

This paper starts by reviewing the protracted Latin American debt crisis extending from the early 1980s to the early 1990s, in order to draw policy analogies for today's situation in the U.S. mortgage securitization market. During the Latin American episode, the Brady Plan, a credit enhancement program, not only injected liquidity into the economy, but also restored tradeability and market depth for sovereign debt. The credit enhancement was achieved through full collateralization of the loan's principal using a zero-coupon U.S. Treasury bond at the 30-year maturity. This measure revitalized the market for Latin American debt because it helped to ameliorate the dual solvency problem affecting both creditors and debtors, and revealed asset prices that were less distorted by low market liquidity and other short-run factors. How is today's situation similar to that of Latin sovereign debt in the 1980s, and what is the contemporary analogy to the Brady bond?

The apparently excessive risk premiums arising from market-liquidity disruptions were central problems during the 1980s debt crisis. Arguably, this situation also characterizes the current securitization crisis. Many observers then and now hypothesized that market participants' risk perceptions in the midst of the crisis were and are excessive, even if before the onset of crisis there was excessive risk taking. Further to today's situation, some analysts argue that several commonly used benchmarks for securitized credit are biased downwards by specific loss recognition rules (which have subsequently been relaxed a bit). Regardless, when market liquidity disappears making everyone worse off, economists say that the pricing system fails to fulfill its allocative role. Such a market failure occurred in the collapse of lending to Latin America in the 1980s and today is suggested by the dramatic decline in securitization starting in 2007 (see Figure 1) and the lack of market depth for these instruments subsequently.

In order to foster new mortgage securitization, we argue that the Federal Reserve and the U.S. Treasury could jointly implement a specific form of cash flow enhancement that has the potential to increase market liquidity by exploiting their advantage supplying 
the scarce market input: trust. Given the constraints and responsibilities faced by both agencies, the suggested plan focuses on getting the most "bang for their buck." In particular, the proposed intervention analogous to the Brady bond reduces the risk of cash-flows that contribute the most to the asset's price-sensitivity to spread-risk. With the appropriate structure, these credit enhancements should also provide a price floor tied to U.S. Treasury securities, thereby reducing the asset's liquidity risk premiums. ${ }^{1}$

We use the general framework first to analyze the Brady bond case. Then we apply the framework to pools of newly-issued mortgage securities, which could include loans used to refinance existing mortgages. We find that the Brady bond enhancement was both effective at reviving the market and a cost-minimizing means of reducing the most important risk (and hence, risk-premium) in pricing the sovereign-debt instrument: the enhancement was to collateralize the bond's principal at the 30 -year horizon. For mortgage pass-through securities, the crucial risk premiums, which have the biggest impact on asset price, are on the cash-flows near the mid-point of their maturity structure; yet the principles regarding the optimal design of this form of credit enhancement are the same as for the Brady bond intervention. ${ }^{2}$ The direct effect of structuring the credit enhancement in this way is that it should have the lowest expected cost for a given reduction in risk premiums. ${ }^{3}$ There is also an indirect effect. If the program succeeds, and overall mortgage markets improve, the likelihood of having to make good on the cash flow enhancement is further reduced, and public-sector payments to private investors in troubled assets would be less likely. Hence, there are two mutually-reinforcing forces that contribute to minimize the cost of the creditenhancement intervention into the market.

\footnotetext{
${ }^{1}$ Chairman Bernanke and New York Fed President Dudley state that "providing investors a limit on potential losses is an important means by which the program stimulates investor demand, even for AAA-rated securities," in their answer to question 7 of the March 20 enquiry by the Congressional Oversight Panel (Bernanke and Dudley 2009). This view seems consistent with the hypothesis that providing a price floor would increase market depth.

2 Despite the difference in embedded options in the reference assets. This is discussed in more detail further below in the text.

${ }^{3}$ Taking into account the probability of actually having to make payments associated with the guarantees.
} 
The paper is structured as follows. Part 2 briefly reviews the current state of the U.S. securitization market. Part 3 reviews the Latin debt experience and the Brady bonds, and Part 4 discusses the methodology underpinning the credit enhancement applied to the current situation. Part 5 concludes, emphasizing how this program might further today's public policy goals of stabilizing and restoring U.S. markets for financing mortgages.

\section{The Current State of the U.S. Market for Asset-Backed Securities}

In the United States today, in conjunction with the disappearance of new securitization, legacy credits for all risk classes are trading at huge discounts. Recent announcements of new Federal Reserve liquidity facilities operating in these markets seems to have partially reduced some of those spreads since December 2008. Other interventions into the market for longer-dated mortgages have brought down interest-rates, at least contemporaneous with the timing of those interventions. But, the U.S. market for securitized assets is not operating as per normal, primarily via private sector entities.

\subsection{The market for credit-based securities remains in disarray}

From a market that accounted for some $\$ 4$ trillion of new credit issuance as of end 2003, the issuance of mortgage-backed securities (MBS), collateralized mortgage obligations (CMO), and asset-backed securities (ABS) has collapsed-see figure 1. The disappearance of the origination market, particularly for many ABS and private-label mortgage securities, is not surprising given that securitization still appears to be very expensive. Signs of minor relief have recently appeared in some ABS markets (see figure 2), possibly starting with the Federal Reserve's announcement of the Term Asset-Backed Securities Loan Facility (TALF) in December 2008. Other actions taken by the Federal Reserve seem to have translated into much lower mortgage rates, and there is some indication of modestly higher levels of MBS originated by government-sponsored 
enterprises (GSEs) during the first quarter of 2009. ${ }^{4}$ Yet the broad MBS market is still trading at large discounts. Figure 3 shows dramatic discounts even for the highest rated ABX series. ${ }^{5}$ Even if the discounts reflected in that widely-cited index exaggerate the actual current market experience for private-label MBS, they do provide some information on the trends for this type of securitization.

\subsection{Legacy mortgage securities vs. new mortgage activity}

The emphasis placed by the Federal Reserve System and the U.S. Treasury on programs like TALF underscore the importance of the securitization process for the availability of credit in the economy. However, these facilities currently focus on shorter maturity assets, with the possible exception of some commercial mortgage-backed pass-through securities (CMBS).

The intervention we suggest exploits the properties of assets generating cash-flows during a relatively longer horizon. Hence our suggested intervention is particularly targeted at reviving securitization markets for new mortgages (including new mortgages to refinance existing mortgages). How does intervening in the new mortgage market address the legacy MBS problem? Many homeowners who refinance mortgages pay down loans that are included in legacy MBS/CMO assets. If structural features of those MBS/CMO assets contribute to their current lack of tradeability, paying down their constituent mortgages would extinguish the assets. ${ }^{6}$ Therefore, encouraging new mortgage securitization could contribute to resolving the problem of legacy assets as well as provide new financing channels.

\footnotetext{
4 The Federal Reserve is purchasing during 2009 large amounts of GSE debt and agency MBS, with the explicit intent of reducing mortgage rates.

${ }^{5}$ This index is based on the pricing of Credit Default Swaps on its 20 component bonds. This pricing is a function of particular definitions of credit events and of the market liquidity of those specific CDSs. Although widely referenced, many question the extent to which the index represents the true value of the underlying assets.

${ }^{6}$ The Federal Reserve System recently increased their 2009 target for straight-out purchases of agency MBS assets to $\$ 1.25$ trillion - another strategy to remove from the market these types of assets, and to raise their bid-quotes.
} 
Figure 4 shows the current importance of mortgage refinancing relative to the overall volume of mortgages granted, which seems to suggest that refinancing is currently the main driver of total mortgage applications (as measured by the Mortgage Bankers Association index of total activity). It seems reasonable to worry, then, about the availability of properly functioning securitization markets for newly-issued mortgages in general, and not only refinancing loans.

\section{Historical Analogy: The Latin American Debt Crisis of the 1980s}

This section develops the main points of analogy between the Latin American debt crisis in the 1980s and the current financial market turmoil. The two periods share important characteristics regarding some broad features of the financial instruments affected, the critical exposure of the U.S. banking system to these troubled assets, and the type and persistence of some efforts to resolve the crisis. The focus then turns to specific features of the public intervention that was central for the resolution of the Latin American debt crisis.

\subsection{The nature of the original obligations and the run-up to the crisis}

There are many broad similarities between the extension of debt to Latin America prior to the onset of the 1980s crisis and the growing importance of asset-backed securitization in recent years. These similarities include the business model of originate/syndicate, an environment of narrowed risk spreads, and the vulnerability of U.S. banks to the ensuing crisis.

\section{The "originate, syndicate" model of lending}

In the 1980s, the largest financial institutions originated loans to developing country markets, and then syndicated these loans to smaller and regional banks. This method was advantageous both for the originators and for those institutions that took on the 
non-recourse obligations, but eventually led to the accumulation of too much risk. ${ }^{7}$ In part the excessive risk-taking was a consequence of the sovereign guarantee afforded to many of these credits. In many respects this model was reused in the securitization markets in the last decade, even if the guarantees were not of a sovereign nature.

Originators of the Latin American loans were able to develop these new markets without retaining the full risk of the assets on their balance sheet (although in the end, their balance sheet exposure was excessive.) Syndicating the debt freed up capital to leverage even further. Buyers of the Latin American credit obligations were able to take a stake in these new markets, getting a high return on apparently low-risk financial instruments without the cost of originating loans or performing due diligence.

Loans to Latin America surged almost five-fold in nominal terms, going from \$130 billion in 1973 to $\$ 612$ billion in 1982 . About 80 percent of the debt was either sovereign borrowing, or had a government guarantee. Most of the debt was denominated in U.S. dollars and issued at floating interest rates based on LIBOR (Cline 1984, pp. 1-4, table 1.1). Borrowing by private entities was not very transparent, meaning that the borrower's ability to repay was not assessed once the credit carried the sovereign guarantee.

In the 2000s, the method of securitization served the same purpose of off-loading the originating lender's exposure, levering-up the financing available, and also earning fees. Eventually the ability of the underlying obligors to repay these collateralized loans became of secondary importance, as had happened decades earlier with syndicated loans to Latin American private borrowers. In the recent securitization episode, the key role of rating agencies in performing due diligence is similar to that played by originating banks in the earlier period, and the role of the sovereign guarantee is played, perhaps, by the underlying cash-flows used as collateral or other internal/external credit enhancements. In some cases the protection provided by collateral was instead attained through derivative instruments, such as long Credit Default Swap (CDS) positions.

\footnotetext{
${ }^{7}$ A non-recourse loan is backed exclusively by collateral specified in the loan contract. In case of default, if the collateral is insufficient to cover the value of the outstanding loan, the creditor bears the residual loss.
} 


\section{The narrowing of risk spreads and an accommodative monetary stance}

In the case of Latin American debt prior to the 1980s crisis there was a remarkable narrowing of risk spreads, apparently implying that financial markets were allocating risk to those most able to bear it. It was also the case that monetary conditions were initially accommodative. Both conditions fueled lending into the new Latin American debt markets. Similar risk-pricing behavior and credit extension in the ABS/mortgage pass-through market characterize the recent securitization episode.

For example, between 1977 and 1981 Argentina and Chile borrowed at rates lower than U.S. 7-year bond rates, and Mexico's spreads were about 50 basis points above the same benchmark. During this period, Canada's new public borrowing was assessed a premium of 262 basis points, while Brazil's premium was only 187 basis points (Lindert 1992, p. 233, Table 8.1).

Even as LIBOR more than doubled from 5.96 percent in 1976 to 14.07 percent in 1979, the spread for Mexico's debt narrowed from 205 basis points to 74 basis points; for Venezuela from 163 basis points to 67 basis points; for Brazil from 220 basis points to 115 basis points, and for Chile from 193 basis points to 90 basis points. Risk spreads over LIBOR continued to narrow for some of these countries even beyond the onset of the debt crisis in 1982 (Balkan 1995, Appendix 4).

\section{Regulators and markets were aware of bank exposure to Latin America}

At the onset of the Latin American debt crisis in 1982, the U.S. banking system was highly exposed to these credits, which were concentrated in about four Latin American countries. The exposure of the banking system was not a surprise when Mexico defaulted in August 1982. So where were the regulators, or for that matter, the market discipline to induce banks to alter their lending strategy before a collapse? The current securitization episode engenders similar questions, although one might suppose greater difficulties in measuring risk exposures and even more opaqueness to both regulators and markets this time around. 
Although by the early 1980s U.S. commercial banks had extended substantive amounts of credit to some 33 developing countries, four Latin American countriesArgentina, Brazil, Mexico and Venezuela-accounted for somewhat more than 70 percent of bank claims of the 17 most highly indebted countries. ${ }^{8}$ By various measures, the exposure of the largest U.S. banks to developing country loans exceeded capital by substantial amounts well before the collapse. In 1977 emerging market debt to capitalplus-reserves of the largest banks exceeded 200 percent and this ratio rose to 232 percent by 1982 when the crisis began (FDIC 1997, p. 203, table 5.1a). In 1982 the exposure of the entire U.S. financial system to the four key Latin American borrowers was 130 percent of capital-plus-reserves and the exposure of the money-center banks alone was 135 percent (calculations from Cline 1995, p. 72, Table 2.11).

In terms of regulatory oversight and market discipline, in 1979 the Office of the Comptroller of the Currency (OCC), the Federal Reserve Board (FRB), and the Federal Deposit Insurance Corporation (FDIC) created the Interagency Country Exposure Review Committee (ICERC), which tracked the foreign exposure of U.S. banks. But also in 1979, the OCC rendered the judgment that the 10 percent rule (a bank's credit to one borrower could not exceed 10 percent of its capital-plus-reserves) did not apply to sovereign debt. Some U.S. banks had already exceeded that limit; following that resolution, they continued to lend more to the same borrowers (FDIC 1997, pp. 203-204). Market discipline also was muted; the stock price growth of large banks exceeded that of the S\&P 500, and their bond ratings did not suffer despite the concentration of exposure to certain Latin American countries (see FDIC 1997, p. 201, figure 5.7).

\section{Crisis in August 1982: interest rates, terms of trade, and the macro environment}

Rising real interest rates at the end of the 1970s and early 1980s altered the risk-return preferences of the holders of the Latin American assets, and certainly altered the obligors' ability to repay their floating-rate loans. The world recession in the early 1980s further undermined the ability of the Latin American countries to repay their debt

\footnotetext{
${ }^{8}$ In turn, these 17 countries alone accounted for about 80 percent of total extensions of bank credit to developing countries. See Cline 1995, p. 62, table 2.9.
} 
through export earnings. At the same time, the appreciation of the dollar implied a much more costly burden of dollar-denominated debt. Finally, the initial rise and then collapse of the price of oil resulted in dramatic changes in the terms of trade for Mexico-the first Latin American country to default in August 1982.

\subsection{Responses to the Latin debt crisis: Baker versus Brady}

Following the Mexico default in 1982, there were two systematic efforts to solve the twin problems of stalled lending to borrowers and the creditors' vulnerable balance sheets. The first effort, the Baker Plan (1984-1988), tried to inject liquidity into the market to solve these twin problems. The second effort, the Brady Plan (1989-1992/1994) ${ }^{9}$ focused on restarting the market for existing loans both to generate new lending and to resolve bank balance sheet problems. The Baker Plan failed; the Brady Plan succeeded. Are there lessons from this experience that could be used in today's crisis?

\section{The Baker Plan: its liquidity focus failed, but bought time for banks}

The Baker Plan viewed the situation in the debtor countries as a liquidity problem exacerbated by their domestic economic policy mistakes. It exhorted U.S. banks to resume lending abroad (indeed, the Baker Plan included targets for foreign bank lending) so long as countries had International Monetary Fund (IMF) and World Bank policy reform programs in place. The Baker Plan bought time for U.S. banks to partially repair their balance sheets, which turned out to be an economically costly delay for Latin American countries. Nonetheless it failed to revive the market for existing Latin American debt or to restart new lending to Latin American borrowers.

The first problem with the Baker Plan was that little new money was channeled to borrowers. Banks did not lend the amount targeted in the Baker Plan, although they lent about two-thirds of that goal (Cline 1995, p. 15). Outstanding loans of the largest U.S. banks to developing countries fell from about $\$ 60$ billion in 1984 to $\$ 45$ billion in 1988 (FDIC 1997, figure 5.4). In addition, the "concerted lending" strategy found less traction

\footnotetext{
${ }^{9}$ Most of the Brady effort was concentrated between 1989 and 1992, but there were still deals being done as late as 1994.
} 
among the non-U.S. financial institutions, which had been somewhat less exposed to the Latin American debt.

Markets in syndicated debt, thin to begin with, did not revive during the four-year Baker Plan. Prices of Latin American country debt dropped in the secondary markets from some 70 cents/dollar in 1987 to 35 cents/dollar in 1989 (Cline 1995, p. 15).

U.S. bank balance sheets improved somewhat during the Baker Plan, in part because official money from the IMF and World Bank replaced private loans in meeting the external financing needs of the Baker Plan participants (Cline 1995, Figure 5.1). By 1986, mid-way through the Baker strategy, a 50 percent haircut on the value of Latin American debt would have eliminated two-thirds of the capital of the nine biggest U.S. banks (Cline 1995, p. 6 and p. 77) rather than wiping out all of the capital (and then some), which was the situation at the start of the crisis. On the other hand, U.S. bank exposure to Latin American debt remained above 120 percent of bank capital, so the balance sheet repair was incomplete. Market discipline kicked-in with equity prices of both large and regional banks under-performing the S\&P 500 (FDIC 1997 , p. 201 and p. 208, figure 5.7).

In sum, the focus of the Baker strategy on liquidity can be regarded as a failure because there was (1) no net new lending, (2) no revival of trading in existing debt, (3) collapsed prices on existing debt, (4) no resolution of bank balance-sheet problems, and (5) continued dependence on official support by both borrowers and lenders. In many respects this is a description of where we stand in the current securitization episode.

\section{The Brady Plan: its solvency focus and the creation of marketable assets}

The Brady Plan (1989-1992/1994) recognized the need to write down the value of the Latin American debt, and negotiated several approaches to do so. It created a market in Latin American debt by swapping illiquid, opaque syndicated loans for a standardized marketable bond. Anticipating large risk premiums resulting from both the borrowers' fragile condition and the unproven nature of the new instrument, the new bonds were significantly enhanced with U.S. Treasuries as collateral. 
Under the Brady Plan, representatives of the debtor country and of the bank creditors negotiated new terms for a new bond that would replace previous debt. Roughly, these new terms were either: ${ }^{10}$ (1) a 30-year bond with fully collateralized principal (a U.S. zero-coupon Treasury), without haircut, and a sub-market fixed interest of approximately 6 percent (market yields were around 10 percent at the time); or (2) a 30-year bond with fully collateralized principal (a U.S. zero-coupon Treasury), after a 3035 percent haircut of the original debt, and interest at LIBOR plus 13/16ths of a percentage point. ${ }^{11}$ In addition to guaranteeing the principal, in both cases $12-18$ months of rolling interest payments were guaranteed.

Banks chose from this menu of new bond contracts to match their balance sheet and earnings needs. Some banks wanted to avoid further write-downs of assets, whereas others could absorb asset write-downs but needed interest streams at market rates. Under the Brady Plan the average write down was 35 percent (Cline (1995), p. 235, see also Table 5.3). Loan forgiveness ranged from 19.8 percent for Venezuela to 80 percent for African debt.

The Brady Plan was not a "new money" plan, for of 18 deals between 1989 and 1994, amounting to $\$ 191$ billion, only $\$ 3.62$ billion in new money was added (Cline 1995 , p. 235, Table 5.3).

\section{Metrics of the Brady Plan's success and the cost of its credit enhancements}

Evidence of the Brady Plan's immediate success was the revival of new lending to the Latin American borrowers. Even though the Brady bond swaps did not include new money, once the write-downs were taken and the marketability of the new instruments revealed, new money came into Latin America. In particular, their bond issuance rose from \$930 million in 1989 to more than \$20 billion by 1993.

\footnotetext{
${ }^{10}$ There were additional options, in particular regarding the profile and interest rate on payments; but these two are the most salient to analyze the overall experience.

${ }^{11}$ It is important to clarify that some authors (see Cline 1995) refer to the bonds of type (1) as "par bonds," even though they would trade at a discount due to their low coupon, and "discount bonds" to those of type (2), which were designed to trade approximately at par value (the coupon rate was variable and close to market yields).
} 
Secondary market prices were another indication of success. From 1989:Q4 to 1993:Q4, secondary market prices rose 128 percent for Mexican debt, 109 percent for Venezuelan debt, 109 percent for Brazilian debt, and 408 percent for Argentina. At the end of that period, per-dollar prices for Brady bonds of type (1), as described above, were about 80-82 cents for Mexico, 71 cents for Venezuela, and 66 cents for Argentina (Cline 1995, p. 249). The implied discounts were close to the original debt forgiven through other options in the Brady plan (for instance the Brady bonds of type (2) discussed above).

Transaction volume in the debt/loan markets to emerging economies revived. From 1993 to 1996 trade in Brady securities was over 50 percent of total volume in those markets; in 1993 they totaled $\$ 1,021$ billion out of $\$ 1,979$ billion, but in 1996 their trade volume reached $\$ 2,690$ billion (Mauro et al. 2006 , p. 21 , Table 2.4). Countries started to retire their Brady bonds around 1997, issuing uncollateralized debt.

Finally, there was little stigma to being a Brady Plan participant. Countries that graduated from Brady programs paid only 75 basis points more to borrow new money compared to countries that never participated in the Brady Plan.

The credit enhancements were an important part of the Brady strategy. How costly were the enhancements for the sponsor institutions? Cline (1995) looks at the data for six countries that accounted for half of the original value of debt included in the Brady Plan. ${ }^{12}$ For these countries, the value of the credit enhancement was $\$ 12$ billion for $\$ 105$ billion of original face value of debt. Funding for the $\$ 12$ billion was provided by the IMF, the World Bank, the Inter-American Development Bank, Japan's Export-Import Bank, and in some cases the beneficiary country's own reserves. Is $\$ 12$ billion a lot? It paid for $\$ 30$ billion of forgiveness (a plus for borrowers) and for approximately $\$ 75$ billion in guaranteed principal (a plus for the creditor). The ultimate value of enhancements that the program required was far below the initial estimates. ${ }^{13}$ Moreover

\footnotetext{
${ }^{12}$ Cline (1995) , p. 264 , Table 5.6.

${ }^{13}$ Cline (1995), p. 265.
} 
the probability that the collateral provided by the program sponsors would be lost was considered extremely small, even during a crisis. ${ }^{14}$

\subsection{Lessons from the Brady bond strategy}

The contrast in outcomes between the Baker and Brady Plans offers a cautionary tale on depending upon liquidity alone to tackle solvency problems of both borrowers and creditors. The Brady bond experience points to three sources of gain: (1) reviving the market, (2) reducing the risk of borrower default, and (3) improving the balance sheet of the creditor.

Reviving the Market

The Brady bonds recreated the market for existing Latin American debt. Their market depth implied that pricing was determined mainly by cash-flow risk and was not dominated by substantial liquidity premiums. It also catalyzed new bond issuance. The U.S. Treasury (UST) collateral reduced the overall risk of the Brady bond, and placed a lower bound for the price of the Brady bonds (the value of the UST used as collateral).

Reduced risk of borrower default.

Access to external financing through the Brady bonds (debt forgiveness and new bond issuance) reduced the risk for three reasons: (1) it was cheaper to finance a given level of debt (lower risk-spread); (2) lower interest rates for the private sector in Latin American countries improved their internal economic conditions; and (3) it reduced the risk of balance of payments issues and/or currency crisis.

Clarified or resolved the balance sheet problems of U.S. financial institutions.

By rejuvenating the market, and improving price discovery, the Brady Plan made valuation of the creditor's balance sheet more transparent. The Brady Plan gave financial institutions a menu of alternative ways to recognize the losses, to best fit the needs of the

\footnotetext{
${ }^{14}$ The structure of the Brady Plan involved the sponsor institutions (for instance the IMF and the World Bank) lending to the beneficiary countries the U.S. Treasury bonds used as Brady collateral. In the event of a country default, the Brady bond buyer would receive the collateral and lose any other cash-flows. In this event, the country would owe the value of the collateral to the sponsoring institutions.
} 
balance sheet. Moreover, the fact that the Brady bonds were marketable allowed institutions to get Latin American debt off their balance sheet entirely, if they wanted to.

How might the lessons from the Brady programs be applied to solving the current problems in U.S. mortgage securitization markets? While some specific features of the current troubled assets make collateralization of specific cash-flows a potential policy option, it is very important to structure this credit enhancement to maximize the benefits from intervention at the lowest possible cost. The next section explores a specific methodology for analyzing the success of the Brady bond credit enhancements, and proposes a similar approach to designing an intervention for the currently troubled mortgage securitization markets.

\section{Key-Rate Durations and the Timing of Credit Enhancements}

Why did the Brady bonds focus on insuring the principal instead of all the coupon payments? We argue that structuring the enhancements on principal maximized the "bang for their (expected) buck." That is, this method was the most efficient use of enhancement "capital". The Brady bond strategy gives us some hints on how to proceed with other types of troubled assets in order to restore the market for securitized debt. We start by reviewing some basic apparatus.

\subsection{The Concept of Duration}

Duration is a key concept for analyzing the Brady bond program and to draw analogies for possible intervention to affect the securitization of mortgage portfolios. First we briefly explain the concept of duration and discuss its role in the pricing of debt. Then we consider two ways in which the Brady bonds and today's distressed mortgage assets differ: the Brady bonds were not amortizing assets such as mortgages, and mortgages have an embedded option (the option to prepay). ${ }^{15}$

\footnotetext{
${ }^{15}$ As discussed below, without this option-characteristic the price effects yield changes obtained using duration alone would provide a lower bound for price changes. We checked that
} 


\section{Total duration}

The duration of a bond is the (semi-) elasticity of its price with respect to changes in yield. This measure is designed to capture the sensitivity of the bond's price to changes in both riskless rates and any risk premiums or spreads.

The duration of a pure discount (zero-coupon) bond maturing at time $\mathrm{T}$ depends importantly on its maturity. In continuous-time-finance it is the case that ${ }^{16,17}$

$$
\frac{d P}{P}=-T \cdot d y
$$

This means that if there is an increase in the bond's yield of 100 basis points (in which case $d y=1)$, the price of the bond $P$ will decrease by $T$ percent. In this case we say that the (total) duration of the bond is T. Note that this is independent of the bond's face value. ${ }^{18}$

More generally, consider a bond that pays cash flows in $N$ future periods. The duration of this bond is given by

(Equation 1)

$$
D=\sum_{j=1}^{N} w_{j} \cdot D_{j}
$$

accounting for positive convexity in the scenario of 100-200 basis points reductions in risk premia would not alter our qualitative results significantly. Prepayment options, though, introduce negative convexity, an issue we discuss later.

${ }^{16}$ In discrete time, (modified) duration is slightly lower than maturity.

${ }^{17}$ Suppose that we buy a zero-coupon bond that pays $V$ at time $T$. Let $y$ denote the current yield on that bond. Then its price today is:

$$
P=\exp (-y \cdot T) \cdot V
$$

Totally differentiating this previous equation with respect to $P$ and $y$ we obtain:

$$
d P=-T \exp (-y \cdot T) \cdot V \cdot d y
$$

${ }^{18}$ For assets with cash-flows in multiple future periods, (total) duration assumes that the discount rate for all cash-flows changes by the same proportion - that is, we have a parallel spot yield curve shift. 
where $w_{j}=P_{j} / P$ is the price of the cash flow paid at time $j$ (this is, $P_{j}$ ) relative to the price of the bond $(P)$, and $D_{j}$ the duration of this single payment (as if it were a pure discount bond by itself).

Therefore the duration contribution of cash flow $j$ to total duration is given by:

(Equation 2)

$$
D C_{j}=w_{j} \cdot D_{j}
$$

When these cash flows are identical and are paid in equidistant periods, the last two expressions tell us that:

1. Cash flows further away in time have a lower price relative to the entire bond. Hence $w_{j}$ drops as the cash flow maturity $j$ increases. This is the direct effect of having more discounting on a constant cash flow.

2. Cash flows further away in time have a higher sensitivity with respect to interest rate changes: $D_{j}$ increases with $j$. As we discussed above, duration of a single payment increases with its maturity.

Hence, depending on which of the two effects dominate, the duration-contribution of each identical and equidistant cash flow will not be constant, and will be lower than the cash-flow maturity.

The concept of dollar duration measures the effect of a 100 basis points change in yield on the bond's price in dollar terms instead of in percentage terms. This will be useful in the technical appendix, providing an intuitive explanation for the optimality of the proposed plan. The dollar duration of cash flow $j$ is given by

(Equation 3)

$$
\begin{aligned}
D D_{j} & =P_{j} \cdot D_{j} \\
& =P \cdot D C_{j} .
\end{aligned}
$$




\section{Using key-rate durations instead of duration contributions}

For assets with many cash flows, it is useful to look at a measure that summarizes the information provided by the duration-contributions of its cash flows. We are interested now in the question: what happens to a bond price if we change the discount rates that apply to cash flows paid around some future date (no farther away than the bond's maturity)?

The semi-elasticity of the bond price with respect to changes in the spot rates concentrated within a neighborhood of 5 years (for instance) is called the "5-year keyrate duration" ${ }^{19}$ For convenience we can form partly overlapping time intervals around 6-months, and also for 2.5, 5, 7.5, 10, 12.5,.., 30 years, for a total of 13 key-rate intervals. ${ }^{20}$ In this way, looking at the profile of the corresponding key-rate durations we obtain in fewer numbers most of the information about the distribution of duration-contributions. These measures make it easier to study the price effects of general change in the Treasury spot yield curve, or of uneven changes in spreads over the spot yield curve. This last application is of central importance in what follows.

Figure 5 depicts a change in the spot yield curve that consists of a parallel shift only for the later-half of the term structure. This steepening of the yield curve is constructed as the sum of the 7 longer-term key-rates (conveniently defined), those that would apply to the time intervals centered around $15,17.5,20, \ldots, 30$ years.

The change in the yield curve is parallel only in the second half of the curve, showing how to construct a steepening of the yield curve using these conveniently defined keyrates. The sum of equal changes in all key-rates would be a completely parallel shift of the spot yield curve, and its effect on price would be approximated by the bond's

\footnotetext{
${ }^{19}$ Suppose that we want to compute the 5-year key-rate duration. We hold constant any spot rates at or before 2.5 years, and at or after 7.5 years. But we linearly interpolate the change between 2.5 years and 5 , and between 5 years and 7.5.

${ }^{20}$ The terms used here for the construction of the key-rates are somewhat non-standard. We define them in this way to obtain time intervals of equal length, with the exception of the first and last ones..
} 
duration. This facilitates computing what fraction of a bond's total duration is contributed by a specific subset of cash-flows, by changing only the corresponding keyrate(s).

\subsection{Key-rate durations in the Brady bond case}

In figure 6 we depict the key-rate durations for 30-year Treasury bonds, and compare them with the historical Brady bonds. ${ }^{21}$ The impression from the figure is that the most important key-rate duration for these long-term 30-year bullet bonds takes place at maturity.

Table 1 below summarizes the relevant numbers from this analysis. The 30-year keyrate duration for a 9 percent 30-year bond is about 9.2 (right-most column in the table). Hence, if the 30-year key-rate is reduced by 100 basis points, that would boost the bond price "today" by 9.2 percent (approximately). ${ }^{22}$ Moreover, the bottom row indicates that this single key-rate contributes 39 percent to the total bond duration.

Table 1: Summary of Key-Rate Duration Analysis for 30-Year Bullet Bonds.

\begin{tabular}{|l|r|r|r|r|}
\hline 30-Year Bond & 6\% Brady (10\% yield) & 3\% Coupon & 5\% Coupon & 9\% Coupon \\
\hline 0.5-27.5 Key-Rate Duration & 6.9946 & 6.7972 & 8.0629 & 9.2062 \\
\hline Total & 10.2208 & 19.0645 & 17.0404 & 15.2132 \\
\hline & & & & \\
\hline Fraction 0.5-27.5 & 0.6843 & 0.3565 & 0.4732 & 0.6051 \\
\hline Fraction 30 & 0.3157 & 0.6435 & 0.5268 & 0.3949 \\
\hline
\end{tabular}

The Brady bond's central feature was its full collateralization of the principal at year 30 with a zero-coupon U.S. Treasury, eliminating the credit spread from its discount rate. Was this the most cost effective strategy to enhance the bond? In considering this

${ }^{21}$ To price these assets we use as benchmark the Treasury yield curve depicted in figure 7 . The Treasury par-yield curve used to derive the spot rates corresponds roughly to the first week of March 2009. For the Brady bond, the same curve was shifted in parallel so that the bond's yield would be 10 percent.

${ }^{22}$ Again, it is important to note that duration is just a first-order effect, but controlling for convexity does not alter the central qualitative features of the analysis. 
question we note that the relevant cost is determined by the present value of the collateral and the probability distribution of potential collateral losses. First compare the cost of buying a zero-coupon U.S. Treasury versus buying a selected set of coupons of intermediate duration equaling the same duration contribution as obtained from the UST. Note that the cost of the collateral at issuance of the security is not equal to the expected cost of the intervention, as one would need to factor in the risk of actually losing the collateral - see the appendix for a detailed discussion of this point.

Of the two most common Brady bonds, we mainly focus here on the type that is least favorable to our case (type (1) above). ${ }^{23}$ This is the 30-year Brady bond with principal equal to 100 percent of the old principal, and a 6 percent coupon rate (below the $\sim 10$ percent market yield). ${ }^{24}$ The key-rate analysis in the last figure and table show that the last cash-flow contributed around a 39 percent of the duration of the bond (bottom row, left column of the table). The remaining duration was distributed over the 59 previous coupon payments.

Next assume that we want to achieve a given percentage change in the bond price. Is it cheaper to insure only some of the coupon payments instead of the principal? As a first step to answer this problem, suppose that a social planner has a total budget of "10 basis points of risk premium reductions" to distribute over the cash-flow discount rates used to price the asset. ${ }^{25}$ The social planner would optimally allocate all those basis points to reduce the risk premium on the principal repayment, provided that the risk premium is at least that much. If this condition is met, it is optimal to use all 10 basis points to reduce the 30-year spot discount rate because it achieves the largest impact on the total price of the bond, while also providing a back-stop on losses.

\footnotetext{
${ }^{23}$ Brady bonds issued with a 35 percent haircut were 30 -year floaters. The basic intuition behind the analysis of spread duration contributions in this is qualitatively the same. Note that in this case the spread duration is different from the interest rate duration (as measured by changes in Treasury spot rates), and we are ultimately interested on spread duration measures.

${ }^{24}$ The bond's cash-flows are priced using a parallel shift of our benchmark par-coupon yield to achieve that 10 percent market yield.

${ }^{25}$ These spot discount rates would be the spot riskless rates plus the risk premium required to correctly value each cash-flow.
} 
Mapping those basis points into dollars is more complex. We consider two aspects of this issue: leverage and expected cost. As we argue below, both provide similar answers for the design of the credit enhancement program.

1. Leverage. To illustrate this point we compute the duration contributions of the 60 coupon payments for the Brady bond case discussed above. The smallest set of coupons that have a total duration contribution (3.07) closest to that of the principal (3.0484) consists of the 20 semi-annual 6 percent coupons paid from year 4.5 through $14 .{ }^{26}$ For a face value of $\$ 100,000$, the cost of purchasing the collateral for the selected set of coupons was $\$ 25,755$. Purchasing "today" the collateral to insure only the principal would cost only $\$ 6,829 .{ }^{27}$ Hence insuring the cash-flows with largest duration contributions (in this case, the principal) lowers the resources that need to be committed today to the credit enhancement program.

An important caveat to this analysis is that in making the comparison between the two policy options (insuring only coupons or only the principal) we made an important assumption that is likely to be violated. This assumption is that the policy reduces the risk premiums embedded into the discount rates for coupons by the same amount. We are simply allocating a given budget of "basis point reductions in risk premium" to each relevant discount rate. If providing collateral for the principal reduces its risk premia much more than the alternative policy of insuring the coupon payments, the former would have a greater impact on prices. Or looking at it in another way, in order to achieve the same price impact the present value of the collateral for the principal could be even lower than stated above. When there are no spot markets to trade all individual cashflows, assessing the risk premium used to discount a given future cash-flow

\footnotetext{
${ }^{26}$ Note that 3.07 is lower than the duration contribution of the last cash flow, because the later also includes the last coupon payment.

${ }^{27}$ By "today" we mean, using interest rates and collateral cost from that time. Using the same spot curve to price this bond gives a results in a price of $\$ 65,165$. This would make this bond at issuance sell roughly at the same price as its main alternative (35 percent haircut on the original principal and variable rate "market" coupon).
} 
bears substantial uncertainty. Targeting the cash flows with largest spread duration contributions could therefore significantly reduce the value of the collateral committed today, which limits the maximum possible losses for the public institution sponsoring the program. In the Brady bond example given above this is both true in a present value sense, and in terms of future dollars in losses; the total payments made by the insurance program in case of loss of the 20 coupon payments selected above would be much larger than paying the principal only.

2. Expected cost. The expected cost is determined jointly by the value of guarantees (and hence leverage) and the probability distribution of losses that would be born by the credit enhancement program. If markets are efficient, the (actual) probability distribution of losses is known to all participants, and agents are homogeneous, then the increase in the asset price and the expected cost should be identical. In this case, providing credit enhancements would be a pure transfer of resources to the private sector.

However, the two crises we discuss in this paper are, quite certainly, cases where the assumptions just mentioned are far from reality. In this case, public intervention in the form of credit enhancements can have price effects, and more generally welfare gains, that exceed significantly the expected cost of intervention. Section 4.4 and section A.3 (appendix) below illustrates this case in a rather general context. From this standpoint, the optimal allocation of the credit enhancement targets cash-flows with the largest duration-contributions because they require the smallest reductions in risk premia to achieve a given asset price change. Therefore, they are more likely to attain the desired price effect for a given expected cost. Alternatively, this can be rephrased as achieving the largest 
expected price increase for a given level of expected cost for the public institution sponsoring the program. ${ }^{28}$

\subsection{Key-rate durations and ABS/MBS-type assets ${ }^{29}$}

Ultimately, this policy paper is not interested in Brady bonds, but in the market for pooled mortgage securities. Hence we next apply the same methodology to this asset type, and find that the largest duration contributions are typically concentrated near the mid-range of cash-flow maturities.

\section{Central distinguishing features of mortgage pools versus "standard bonds"}

There are two specific features that differentiate mortgage pass-throughs from standard bullet bonds. First, mortgages are amortizing loans, because the principal is repaid over time and not in a single payment at maturity. In the absence of unscheduled prepayment, they consist of a sequence of equidistant identical cash-flows, unlike the Brady bonds. The duration contributions of those equal cash-flows was briefly discussed after introducing Equation 2 above.

Second mortgage borrowers have a prepayment option-the lender has sold this form of call option. Lower interest rates increase the cost of the option for the lender, partially offsetting the (now) higher discounted value of the expected mortgage payments. Hence pre-payment risk reduces the duration of the bond when rates decline. Also, as in the case of defaults, the prepayment option makes those cash-flows accruing later in time less certain. ${ }^{30}$ But mortgage prepayments may take place for many

\footnotetext{
${ }^{28}$ The appendix is entirely dedicated to provide a short analytical framework to assess this claim in the context of a mortgage pass-through security.

${ }^{29}$ We checked that accounting for positive convexity would not alter our results significantly. Nonetheless the prepayment option embedded in mortgages introduces the possibility of negative convexity. In this latter case, the price increase due to a reduction in spreads/yields would be over-estimated by duration alone. For an analysis where this feature of a mortgage pass-through is explicitly accounted for (instead of assuming a specific prepayment speed given by a PSA multiple), see Ho (1992).

${ }^{30}$ But unlike defaults, the prepayment option also increases the risk of earlier cash flows (reinvestment risk).
} 
reasons other than interest rate movements, such as the need for the homeowner to move.

\section{Key-rate durations for mortgage pools}

How do amortization and prepayment impact the choice of which cash-flows to enhance? Below we explain that in order to maximize the effect on asset prices of a given reduction in risk-premium, the policy should provide credit enhancements affecting the cashflows in the neighborhood of years 5-15 (or a subset of years in this mid-range) for a pool of 30year fixed rate mortgages.

A key issue in pricing mortgage-backed securities is the expected impact and likelihood of prepayments. The following analysis assumes particular PSA benchmark multiples to capture the effect of prepayments, instead of using a probabilistic model of prepayment to price the underlying embedded option. ${ }^{31}$ However, regarding prepayment due to interest rate risk, we believe that the general message from our analysis is likely to be quite robust because:

1. At the time of this writing (April 2009), mortgage rates were at historical lows. The contract rates reported by the MBA for 30-year fixed-rate mortgages for March 2009 averaged 5 percent, their lowest level for this series. Rates reported by the Federal Home Loan Mortgage Corporation for March also show an all time low, with data going back in time to 1972.

2. The U.S. public sector had recently implemented aggressive policies with the objective of revitalizing the housing market by lowering mortgage rates. Those policies ranged from purchases of government sponsored enterprise (GSE) debt (to lower GSEs' cost of funds), to outright purchases of agency MBS. The recent announcement of a Public-Private Investment Program to free capital currently tied to legacy loans / securities, and the possible expansions of the TALF have

\footnotetext{
${ }^{31}$ The Public Securities Association (PSA) prepayment model assumes that prepayment rates increase over the first 30 months of the mortgage, and stay constant thereafter. The standard prepayment speed, usually called 100 PSA, starts with prepayments at 0 percent on the first month and increase thereafter by 0.2 percent each month until reaching 6 percent on month 30. After month 30, 100 PSA assumes that the prepayment rate stays constant at 6 percent per month. Using 200 PSA to model prepayments, would indicate that the analysis uses prepayment rates that are twice as high as those in the 100 PSA benchmark.
} 
similar goals. Most of the spending through these interventions has been scheduled to take place before the end of $2009 .{ }^{32}$

3. The type of cash-flow enhancements that we suggest for pools of new mortgages (and for refinancing of legacy mortgages) should translate into lower rates on the underlying loans. Therefore prepayment of these mortgages should be less subject to interest-rate risk.

Moreover, Ho (1992) performed a similar duration analysis for mortgage passthroughs by taking into account changes in the value of the underlying pre-payment option (which included any negative-convexity effects). His reported results are qualitatively similar to ours. Even if the pre-payment option were out of the money, negative convexity could still be a relevant concern because of the time value of the option. The price effect of a reduction in a spot rate could be over-estimated by duration alone. Nonetheless, given the reasons just provided, we believe that duration alone is still informative for the general analysis here, at least by underscoring the first-order effects of our policy proposal.

Key-rate durations for mortgage pass-through securities under different prepayment assumptions are displayed in figure $8: 33$ The profile of these key-rate durations suggests that in order to maximize the effect on asset prices of a given reduction in risk-premium, "guaranteeing" a minimum cash-flow from years 5-15 (or a subset of years in this mid-range) would have the largest price impact. For example, at 200 PSA, reducing risk-premiums in that range uniformly by 100 basis points would boost today's spot price by 4.6 percent. ${ }^{34}$

\footnotetext{
32 Arguably, the first announcement of the policies has had a larger effect than the implementation of the interventions themselves. Yet, many aspects regarding the public-private partnership and the TALF still present uncertainties.

${ }^{33}$ We have aggregated cash flows semi-annually to simplify the analysis.

${ }^{34}$ The key-rate duration chart was computed for a mortgage pass-through portfolio of newly issued 30-year fixed-rate mortgages at a 5.15 percent. This is the last available rate reported by Freddie Mac Primary Mortgage Market Survey at the time of this writing (March 6, 2009). Instead of looking only at the option value determined by the likely path of interest rates, we focus on 200 PSA for which the implied spread is 2.16 percent. Figure 11 displays the expected monthly cash flow profile for a $\$ 100,00030$-year fixed-rate mortgage with an assumption of 200 PSA. The figure decomposes the cash flow in three components: prepayments, scheduled principal repayment, and interest. These cash flows have been aggregated semiannually to simplify the analysis. Using PSA as a benchmark for pre-payments is consistent with industry standards in many applications.
} 
Does this observation on timing hold for other PSA multiples? Table 2 shows that for somewhat higher PSA multiple assumptions, the qualitative results discussed in the last paragraph are essentially preserved. In particular, most of the sensitivity to spreadrisk is concentrated in the medium-term, even though higher PSA assumptions shift the timing of cash-flows forward in time. Even for using 400 PSA the key-rates between 5-15 years still contribute 66 percent of total duration. ${ }^{35}$ Why are these conclusions relatively insensitive to PSA multiples? Cash flows assumed by the PSA benchmarks peak always at 2.5 years, when the conditional mortgage prepayment rate (CPR) is assumed to reach its maximum and to remain constant thereafter. ${ }^{36}$ However, whereas those cash flows are proportionally quite large and represent an important fraction of the asset value (high $w_{j}$ ), they take place too early to significantly contribute to duration (they have a low $D_{j}$ in equation 1 above). ${ }^{37}$

\section{Table 2: Summary of Key-Rate Duration Analysis for 30-Year Mortgages.}

\begin{tabular}{|l|r|r|r|r|}
\hline 30-year Mortgage & \multicolumn{1}{|c|}{ 100 PSA } & \multicolumn{1}{|c|}{ 200 PSA } & \multicolumn{1}{|c|}{ 300 PSA } & \multicolumn{1}{c|}{ 400 PSA } \\
\hline 5-15 Key-Rate Duration & 4.5940 & 3.9484 & 3.2076 & 2.5551 \\
\hline Total & 7.3563 & 5.5417 & 4.5095 & 3.8512 \\
\hline & & & & \\
\hline Fraction 5-15 & 0.6245 & 0.7125 & 0.7113 & 0.6635 \\
\hline
\end{tabular}

It is important to underscore that the effects in Table 2 do not account for price increases resulting from reductions in market-liquidity risk premiums (or alternatively, the presence of inefficient pricing of risk). We consider these effects an important gain for the policy we propose. Section 4.4 and section A.3 (Appendix) below elaborate further on these gains derived from providing a floor to the value of the enhanced cash

\footnotetext{
${ }^{35}$ Ho (1992) finds a similar pattern taking into account the underlying option price changes rather than adjusting the cash flows via PSA.

36 This maximum is 6 percent per annum for 100 PSA.

${ }^{37}$ The appendix discusses the determination of the optimal time-allocation of cash flow enhancements at a slightly more technical level.
} 
flows (and hence for the asset) given by the value of the U.S. Treasury securities used as collateral. ${ }^{38}$

A more detailed analysis looking at the duration contribution of each semi-annual cash flow supports the main message behind our policy proposal: early and late cash flows do not matter much in determining the interest-rate sensitivity of a mortgage. Figure 9 shows the cumulative duration contribution function. The 20 semi-annual cash flows paid from year 3 to year 12.5 under the assumption of 400 PSA still contribute 70 percent of the total duration (2.69 out of 3.85).

\subsection{Credit enhancements and spillover gains}

As we underscored earlier, the collateralization of the Brady bond principal also had the potential to reduce the likelihood of sovereign defaults. It directly increased both the borrower's ability (reducing the potential for currency runs and other macro problems) and willingness (low servicing costs decrease the domestic political cost of not defaulting) to repay. Therefore, the strategy of providing a credit enhancement for the cash flow contributing most to the bond's price sensitivity to changes in spreads not only yielded the largest asset price gain at the lowest cost but also had the indirect effect of reducing the likelihood of default-and hence the likelihood that the program would lose the collateral. Therefore a successful intervention of this type further reduced its own cost by improving macroeconomic outcomes.

In both the Brady bond case and for mortgage pass-through securities, the optimal allocation of credit enhancements targets cash flows that are somewhat distant from the present and its accompanying financial turmoil. If the credit enhancement program is effective in regenerating market activity, the actual probability of making the payments associated with the "enhancement" might be lower. Hence, there are two mutuallyreinforcing positive effects obtained from fine-tuning the timing of the guarantees.

\footnotetext{
${ }^{38}$ Despite mortgages have a real asset as collateral, here we consider providing additional collateral for specific cash-flows.
} 
Another central feature of the Brady program was that it altered the market's perception of risk not only for the Brady instruments, but also for other uncollateralized obligations of the debtors, as became evident after 1997. This was achieved in part by reducing the risk premiums linked both to thin market activity and to default risk, which may have had spillovers to other similar assets. This spillover gain was manifested in the rapid boost of secondary market prices of Latin American debt and the resumption of lending to these markets.

\section{Implementing the enhancement for mortgage pass-through securities: the liquidity effect}

Our key-rate duration analysis revealed that enhancing the mid-term cash flows of the mortgage pass-through would generate the greatest increase in the asset's price today for a given cost. ${ }^{39}$ This enhancement could be achieved by collateralizing (partially or even fully) the expected cash flow with a Treasury STRIPS. Such an enhancement would put a floor under the asset price-in this case, the floor would be determined by the price of the corresponding Treasury STRIPS. Such an enhancement could be replicated through a chain of sequentially maturing European put options over the time period covered by the enhancement. In this case, the guarantor would be writing the options, with a strike price equal to the guarantee (the Treasury STRIPS bond). ${ }^{40}$

Establishing a positive price floor for mortgage pools reduces the scale of potential losses due to fire-sales by other market participants. This might reinvigorate the U.S. market for mortgage pools by reducing the liquidity component of the risk premium. Bolstered by the credit enhancement, the ensuing transactions volume would facilitate price discovery and the market-consistent risk-premium pricing, rather than perpetuate the current situation where the fundamentals of risk are being confounded by the lack of

\footnotetext{
${ }^{39}$ A similar analysis can be performed for other ABS, although their maturities might be too short to make such an intervention cost-effective.

${ }^{40}$ The underlying asset covered by the option maturing at time $t$ would be the cash-flow paid at $t$. When the cash flow falls below the strike price (face value of the STRIPS), the investor would exercise the options selling the cash flow to the Fed.
} 
market depth. ${ }^{41}$ Section A.3 (Appendix) below discusses the role of liquidity risk premiums within the analytic framework described in the Appendix.

\section{Enhancements and potential gains to the issuer based on trust}

In behavioral finance, it is widely accepted that when market "noise" makes arbitrage impossible (by making any arbitrage attempt subject to risk), it is possible that all agents know the correct fundamental asset values yet nobody is willing to take sufficiently large positions to eliminate the price inefficiencies. When there is evidence of inefficiencies in the market due to persistent lack of both trust and market depth, a comparative advantage in the business of correcting these market failures emerges for the Federal Reserve and the U.S. Treasury. That is, the Federal Reserve and the U.S. Treasury combined can partly rectify both issues of trust and market depth when private market participants cannot do so alone. In addition there is the possibility for the Federal Reserve and the U.S. Treasury to extract rents in the process, reducing the intervention cost for the tax-payer.

Suppose that the distribution of cash-flows implied by current or recent bid-quotes (henceforth, the "bid-implied distribution") are based on a mean-preserving spread of the actual distribution of cash-flows. ${ }^{42}$ For simplicity, we assume that the corresponding "ask-implied distribution" is based on the actual distribution of cash-flows. ${ }^{43}$ In vernacular, suppose given market-depth impairments and other information problems, potential private buyers think the asset value is based on the "bid-implied distribution," whereas if the market valued the assets based on credit and prepayment risk alone, the "ask-implied distribution" would mainly determine the equilibrium price. This divergence between bid- and ask-implied distributions could also be motivated by

\footnotetext{
${ }^{41}$ This is particularly so in a context in which market depth is perceived to be persistently low in the near future. This results in more price volatility and higher perceptions of risk.

42 Preserving the mean is not central to our argument. As pointed out later, the important part is that there exists a non-zero cash-flow value where the ask-implied CDF crosses the bid-implied CDF from below.

${ }^{43}$ This could also be easily relaxed with small changes in our argument, but this choice makes the exposition simpler.
} 
misperceptions of the underlying cash flow risk. ${ }^{44}$ We are interested in the distance between those two distributions for low levels of cash-flow realizations because targeting enhancements only to this area maximizes the program's returns (or minimizes its cost). ${ }^{45}$ Figure 10 depicts such a situation in terms of the corresponding probability density functions (PDFs) to facilitate the discussion.

The gray area indicates the social surplus that could be generated by the introduction of a cash-flow enhancement that targets lowering risk perceptions for potential buyers, even if that risk is only due to a lack of market depth. The central result is that if buyers perceive more risk in the value of a future cash flow than is justified by the cashflow itself, then there is room for the "enhancement" supplier to extract a positive expected profit.

Therefore, providing the insurance is not a zero-sum game, since asset prices should increase by more than the expected cost for the program sponsor.

The cash flow enhancement could ensure a payment equal to the Critical Insurance Level in the figure (denoted by CIL), given by the point where the two distribution functions cross. The maximum price that the private sector would pay for this is the bidimplied partial expectation over [0, CIL] which is by construction higher than the actual (or "ask-implied") partial expectation over the same support. ${ }^{46}$ Hence the program's expected profit would be positive because the increase in the market price would exceed the expected cost of supplying this guarantee. As the bid-implied distribution converges back to the "true" distribution, and trust among private actors returns to the marketplace, equivalent insurance could be bought from the private sector at a lower price. This way, the responsibility of the cash-flow enhancement could be transferred from the public guarantor to the private sector - ensuring an exit strategy for the public guarantor.

\footnotetext{
${ }^{44}$ The only requirement for this exercise is that there be some market failure making the beliefs of potential buyers different from those of the seller-the reader can fit into this framework their prefered reason for today's crisis.

45 The two distributions are lognormal with (geometric) mean 1, but the standard deviation of the bid-implied distribution ( 2.53 percent percent) is a 56 percent percentlarger than the actual one. The Critical Insurance Level is 0.225 , its maximum market price 0.043 and its actual expected cost 0.021 . Hence the net expected profit is a 10 percent percent of the insured amount.

${ }^{46}$ The (few) equations showing this are available from the authors upon request.
} 
Increasing the enhancements further beyond the CIL could still be profitable, but it would increase the probability of making a larger payment without being able to increase the premium by an offsetting amount. This would increase the risk per dollar of guaranteed cash-flow.

Hence, under the assumption that there is a gap between the bid- and ask-implied distributions, the Federal Reserve and the U.S. Treasury are at an advantage relative to the private sector to undertake this type of enhancement because they can easily provide two currently expensive inputs for financial markets: (1) liquidity and (2) trust.

\section{Potential effects on mortgage default rates and moral hazard}

Our policy proposal might improve incentives to re-negotiate non-performing mortgages. This incentive would come from (at least) two sources:

1. The higher prices paid for "enhanced" mortgage pools might make it profitable to reduce the outstanding loan values of some non-performing loans.

2. Lower loan-to-value ratios would allow for a larger over-collateralization layer. This would facilitate the inclusion of other performing mortgages in the “enhanced” pool.

However, on the lender's side, there is a risk of ex-post moral hazard, a typical downside of insurance. Offering this type of enhancement on newly-issued mortgage pools (which could include refinancing of existing mortgages) would only make sense if the underlying mortgages were of sufficient quality, for instance with relatively low loan-to-value and debt-to-income ratios, and low mortgage rates.

\section{5: Summary and Conclusion}

From the Latin American debt episode we concluded that just injecting liquidity did not revive the market for emerging market debt and loans. Moreover, the costs of delaying the workout to borrowers (macroeconomic, political, and social), creditors (equity valuation), and the global financial system were large. The Brady Plan recognized that 
both borrowers and creditors were insolvent and offered a menu of options to recognize some of the loss in value of the underlying assets. But the success of the Brady Plan was importantly related to a specific form of cash flow enhancement. Specifically, it guaranteed the cash flow most sensitive to risk premiums, which was the principal value of the 30-year bond. Our analysis showed that this timing was the most costeffective means to solve the dual solvency issue affecting both borrowers and creditors. In addition, the creation of marketable Brady bonds rejuvenated the market for existing Latin American debt and promoted extension of new debt to this region, unfreezing these markets and yielding system-wide improvements. Finally, these spillover gains, in conjunction with the far-dated credit enhancement (the zero-coupon 30-year U.S. Treasury collateral) reduced the probability of ever having to make any payment as a result of the institutional insurance.

Currently the situation in the U.S. mortgage securitization markets parallels in some key relevant dimensions the Latin American credit market standstill of the early 1990s. Liquidity and capital injections have not revived the markets nor helped in any significant way the market price discovery for these assets. This problem is evidenced by the practical disappearance of the private mortgage securitization market coupled with wide bid-ask spreads for those assets.

Using duration analysis for the Brady bond case, we then draw analogies for the current problems in the U.S. market for mortgage securities. The duration contribution approach indicates that the optimal policy for mortgage pools does not involve providing any guarantee for the most immediate cash flows. Rather, the optimal timing of cash flow enhancements should focus on the cash flows that are most important in determining the sensitivity of the asset price to changes in risk premiums - which for the case of mortgage pass-throughs involve cash-flows typically well beyond 2-3 years from the date of issuance. We provide a technical appendix with a simple analytic framework that illustrates how this optimal set of cash flow maturities should be picked. The type of policy suggested could provide a lower bound for asset prices by linking their value to the price of Treasury STRIPS. This, in turn, would contribute to the reduction of the 
apparently excessive liquidity risk premiums involved in the pricing of these securities. The size of these risk premiums suggests that this type of intervention could additionally yield expected profits for the entity providing the cash flow enhancements. Given the current scarcity of both liquidity and trust as crucial inputs for the frictionless functioning of financial markets, the U.S. public sector possesses a comparative advantage in providing solutions that rely on those two inputs.

Finally, we point out that although our proposed intervention mainly targets new mortgage securitizations, it could play an important role in refinancing legacy mortgage-backed securities. Allowing in the program mortgages only above a certain threshold of credit quality could provide lenders with additional incentives to renegotiate terms of currently non-performing loans, which would reduce default rates and hence, the likelihood that the public program would make any payment associated with the program.

In sum, the duration analysis proposes a strategy to (1) revive the U.S. market in securitized assets, particularly mortgage pools, (2) reduce the likelihood of default of the borrower, and (3) contribute to improving creditors' balance sheet conditions. Importantly, key-rate duration analysis shows how to achieve these outcomes in the most cost-efficient manner. Given the budgetary outlays to date, considering cost effective strategies to mitigate the financial crisis and achieve market-improving outcomes should receive high priority consideration. 


\section{Appendix: Description of the Basic Model}

This appendix illustrates the optimality of allocating cash-flow enhancements over time as described in the main text. Many of the modeling assumptions below are used to simplify and shorten the exposition of the main points discussed in the paper. We show that finding the optimal cash-flow enhancements boils down to determining the time interval they target, conditional on attaining "today" a specific effect on the asset price. More precisely, this model provides the solution to the problem of maximizing the expected impact on the price of a given asset, for a given expected cost (the dual problem of cost minimization). It also briefly discusses the role of market depth and how it relates, on the one hand, the expected price impact of an intervention with, on the other hand, a given expected cost.

Here we restrict ourselves to (partial) insurance policies that either insure only one cash-flow, or all the cash-flows taking place within a particular time interval. Nonetheless, subject to some regularity conditions, any other structure for the insurance (such as insuring cash-flows in disjoint intervals) can be ruled out.

\section{A.1. Timing of the cash-flow enhancements}

The asset pays cash-flows continuously over the time interval $(0, T]$, where $T$ is the date of the asset maturity. The cash-flows are strictly positive over the entire life of the asset. By construction, this asset can be seen as the aggregation of smaller zero-coupon bonds in continuous time with face value $F(t)$, payable at time $t$. We assume that $F(t)>0$ in the relevant time interval, and is continuously differentiable over $(0, T)$. For simplicity the riskless spot-yield curve is also held constant at $1>r>0$. Hence if the payment of cash-flow $F(t)$ is certain, its price today is

$$
P_{\text {safe }}(0, t)=\exp \{-r \cdot t\} \cdot F(t) \text {. }
$$

Pricing a risky cash-flow $F(t)$ involves the use of a risk-premium over the riskless rate $r$, yielding the expression 


$$
P_{\text {risky }}(0, t)=\exp \{-(r+a) \cdot t\} \cdot F(t)
$$

where $a>0$ is the risk premium.

Here we first assume that the only source of risk is the probability of losing the cash flow $F(t)$. In the case of mortgage pass-through securities, this loss could be due either to defaults or prepayments. Later on in this appendix, we allow for other sources of risk (also see the discussion in section 4.4 in the main text), but at the moment this assumption suffices to highlight the main insights.

In this model, the probability of losing a specific cash flow increases with its maturity date. In particular, we assume that this probability increases by a constant rate $p>0$ per unit of time. Hence, the probability that the cash flow will not have experienced this negative credit event (total loss) before it is due is given by

$$
\operatorname{Pr}(t)=\exp \{-p \cdot t\} \text {. }
$$

With this structure of risk, the price of a risky claim to $F(t)$ at time $t$ is given by

$$
P(0, t)=\exp \{-(r+p) \cdot t\} \cdot F(t)
$$

and hence, the risk-premium on this cash flow without any credit enhancement is $a=p$

Suppose that there is some (probably partial) guarantee on cash flow $F(t)$. This reduces the spread necessary over the riskless rate to discount the cash flow. In particular we have $a<p$, resulting in a price (with enhancement) equal to

$$
\begin{aligned}
P_{E}(0, t) & =\exp \{-(r+a) \cdot t\} \cdot F(t) \\
& >\exp \{-(r+p) \cdot t\} \cdot F(t) .
\end{aligned}
$$

In particular, we will be looking at interventions that reduce the risk premium by a fixed amount. Hence we define for convenience

$$
\delta \equiv p-a \quad \text { such that } \quad p \geq \delta>0 .
$$


The expected cost of reducing the risk-spread at time $t$ by $\delta$ is

$$
E C(t, \delta)=F(t) \cdot[\exp \{-(r+a) \cdot t\}-\exp \{-(r+p) \cdot t\}]>0 \quad \text { since } p>a \text {. }
$$

This last expression illustrates that the expected cost of reducing the risk spread is exactly equal to the increase in the asset's price. Of course, this result hinges crucially on the efficiency of financial markets. Because of our emphasis on the concept of duration in the main text, we see that a first-order approximation to this expression results in:

$$
\begin{aligned}
E C(t) & \approx F(t) \cdot \exp \{-(r+p) \cdot t\} \cdot t \cdot \delta \\
& \approx F(t) \cdot \exp \{-(r+p) \cdot t\} \cdot D(t) \cdot \delta \\
& \approx D D(t) \cdot \delta
\end{aligned}
$$

where $D(t)=t$ is the duration of the cash flow accruing at $t$, and $D D(t)$ is its dollar duration. From now on, we take those approximate relationships as exact (see the caveats discussed in the main text regarding convexity and prepayment options).

Hence, in order to achieve a given increase in the asset price (aggregating the price increases for the relevant cash-flows) the total expected cost is fixed and given by

$$
\begin{aligned}
E C\left(t_{1}, t_{2}\right) & =\int_{t_{1}}^{t_{2}} E C(t) d t \\
& =\int_{t_{1}}^{t_{2}} D D(t) \cdot \delta \cdot d t,
\end{aligned}
$$

where the interval $\left[t_{1}, t_{2}\right]$ indicates the period covered by the cash flow enhancement program.

Attaining an increase in the asset price $\Delta P$ costs the same no matter in what time interval where the credit enhancements are allocated. Since we want to target our intervention on an interval $\left[t_{1}, t_{2}\right]$ we can look for our solution holding $E C(t)=\overline{E C}$, a constant at each point in time within that interval. The total cost between $\left[\tilde{t}_{1}, \tilde{t}_{2}\right]$ would therefore be

$$
E C\left(\tilde{t}_{1}, \tilde{t}_{2}\right)=\left(\tilde{t}_{2}-\tilde{t}_{1}\right) \cdot \overline{E C}
$$


Note that relying on risk premium reductions larger than $p$ would not be possible, and hence the policy would be ineffective. At a point in time $t$, the necessary reduction in risk-premium is given by

$$
\delta(t)=\frac{\overline{E C}}{F(t) \cdot \exp \{-(r+p) \cdot t\} \cdot t},
$$

but this reduction still has to satisfy the constraint $\delta(t) \leq p$. Note that here we recognized that the risk-premium reduction could vary over time, and hence should be denoted as $\delta(t)$.

Acknowledging the uncertainty around any estimate of $p$, we therefore want to allocate the enhancements in an interval $\left[t_{1}^{*}, t_{2}^{*}\right]$ that solves the following problem

$$
\begin{aligned}
& \min _{\left\{t_{1}, t_{2}\right\}} \int_{t_{1}}^{t_{2}} \delta(t) d t \\
& \text { s.t. } E C\left(t_{1}, t_{2}\right)=\Delta P^{*} \\
& T \geq t_{2} \geq t_{1}>0 \\
& \delta(t) \leq p
\end{aligned}
$$

where $\Delta P^{*}$ is the desired price change. It this value is too high, there might be no solution to the problem.

In order to avoid complications due to the last constraint being binding, for the analysis of mortgage pass-through securities we assume that $F(t) \cdot \exp \{-(r+p) \cdot t\} \cdot t$ is strictly concave, so that we can restrict ourselves to $t_{1}<t_{2}$ (see the discussion below of the second order sufficient conditions for optimality). This strict concavity assumption is relaxed below in discussing the Brady bond case, or more generally certain assets with much larger cash-flows at high maturities.

Hence, without the last constraint, the problem Lagrangian is given by 


$$
\begin{array}{r}
\Lambda\left(t_{1}, t_{2},\left\{\lambda_{i}\right\}_{i=0}^{3}\right)=\int_{t_{1}}^{t_{2}} \delta(t) d t-\lambda_{0} \cdot\left(\int_{t_{1}}^{t_{2}} F(t) \cdot \exp \{-(r+p) \cdot t\} \cdot t \cdot \delta(t) d t-\Delta P^{*}\right) \\
+\lambda_{1} \cdot t_{1}-\lambda_{2} \cdot\left(t_{2}-T\right)-\lambda_{3} \cdot\left(t_{1}-t_{2}\right)
\end{array}
$$

where $\lambda_{i} \geq 0$ for all $i=0, . ., 3$ in any solution.

The first order conditions for an interior solution to this problem (where only the first constraint binds) yield

$$
F\left(t_{1}\right) \cdot \exp \left\{-(r+p) \cdot t_{1}\right\} \cdot t_{1}=F\left(t_{2}\right) \cdot \exp \left\{-(r+p) \cdot t_{2}\right\} \cdot t_{2}
$$

although a more complete analysis considering possible corner solutions is available from the authors upon request.

Given an initial and terminal value for the time period of the intervention, which we denote as $\left\{t_{1}^{*}, t_{2}^{*}\right\}$, the second-order (sufficient) conditions for a minimum of the optimization problem described above are

$$
\begin{aligned}
& \frac{F^{\prime}\left(t_{1}^{*}\right)}{F\left(t_{1}^{*}\right)} \leq\left[1-(r+p) \cdot t_{1}\right] \\
& \frac{F^{\prime}\left(t_{2}^{*}\right)}{F\left(t_{2}^{*}\right)} \geq\left[1-(r+p) \cdot t_{2}\right]
\end{aligned}
$$

in an interior solution. Because $F(t)$ is continuously differentiable, when those two sufficient conditions hold with a strict inequality, then $t_{1}^{*}$ and $t_{2}^{*}$ fall on either side of the point where the duration contribution function attains a maximum (the required $\delta(t)$ to achieve a given expected cost is minimized).

If $F(t)$ is constant, then the relevant expression for the first-order condition with interior solutions is

$$
\exp \left\{-(r+p) \cdot t_{1}\right\} \cdot t_{1}=\exp \left\{-(r+p) \cdot t_{2}\right\} \cdot t_{2} \text { with } t_{1}<t_{2} .
$$

We can easily see that the function in either side is given by 


$$
f(t, r, p) \equiv \exp \{-(r+p) \cdot t\} \cdot t>0
$$

which is strictly concave in $t$, and with a maximum at $t=1 /(r+p)$ for any pair $(r, p) \in \mathbf{R}^{++}$.

In figure 12 we assume that the expected cost $(E C(t))$ equals 0.10 for all $t$. Then we plot the required $\delta(t)$ and the corresponding $f(t, r, p)$ for $(r+p) \in\{0.15,0.20,0.25\}$. Those three cases are depicted by the blue, green and red curves respectively. The feasible area where $\delta(t) \leq p=0.10$ is shown in yellow in the upper panel. The segment of time where a given $\delta(t)$ curve intersects this yellow area determines the feasible time range $\left[t_{1}, t_{2}\right]$ to consider in determining which cash-flows the enhancement program should target. For the case $(r+p)=0.25$, represented in red, the feasible time range is shown by the double red arrows (in both the upper and lower panels).

Clearly the lowest necessary values belong in intervals that are both removed from the present, and gravitating in the 2-20 years sector of the yield curve. Given a value for $\Delta P^{*}$ it is easy to numerically find the optimal time period $\left[t_{1}^{*}, t_{2}^{*}\right]$.

The desired (absolute) price increase would is then given by

$$
\Delta P^{*}=\left(t_{2}^{*}-t_{1}^{*}\right) \cdot \overline{E C} .
$$

\section{A.2 Analysis for Bullet Bonds}

In this section we assume for simplicity that $F(T)>0$ consists only of the principal repayment. The strict concavity assumption used above in section A.1. might be violated for bullet structures, a case that includes the Brady bonds. In this instance, for a given feasible price change $\Delta P^{B}>0$ the smallest required $\delta(t)$ could be attained at a corner solution where $t_{1}^{*}=t_{2}^{*}=T$. In this case providing an enhancement only for the principal would be the optimal policy as long as completely reducing its risk attains the target increase in price. This is, 


$$
\frac{\Delta P^{B}}{F(T) \cdot \exp \{-(r+p) \cdot T\} \cdot T} \leq p
$$

If this condition is not met, then the optimal policy would consist of fully insuring the principal payment and some coupons. The insurance of the principal would result in an increase in price given by

$$
\Delta P_{1} \equiv F(T) \cdot \exp \{-(r+p) \cdot T\} \cdot T \cdot p
$$

The problem would then have a second stage where the optimal timing considers only coupons and we would be interested in an interior solution for $t_{1}^{*}$ and $t_{2}^{*}$. Given this value, we then solve the same problem to determine the interval $\left[t_{1}, t_{2}\right]$ where the coupon cash-flows should be insured, with the constraint $t_{2}<T$. In this second step of the problem, the target price increase would then be given by

$$
\Delta P^{*}=\Delta P^{B}-\Delta P_{1} .
$$

Here it is important to highlight, once more, that $p$ is quite likely not known with certainty. Moreover, it is quite likely time varying. Hence determining $\Delta P^{*}$ by first computing $\Delta P_{1}$ from the start could be a challenge.

\section{A.3. Market-Liquidity Risk ${ }^{47}$}

This section connects in important ways with section 4.4, as below we consider how market liquidity problems could have caused part of the large bid-ask spreads observed in many current debt securitization markets. For both the Brady bond case and the

\footnotetext{
${ }^{47}$ The analysis in this section, as well as that in section 4.4 can be adapted to fit other possible explanations for the wide bid-ask spreads (wide enough to make a necessary market practically vanish). As in section 4.4, the relevant features of the analysis quite possibly map well into the reader's alternate preferred explanation. Nonetheless, at the moment we admit to be unable to say much regarding the hypothesis that this "magic" gap in valuations by potential buyers and potential sellers is due to "irrationality." Essentially we lack a reasonably good rational model of irrationality, and remain open to suggestions.
} 
securitization of new mortgages today, market-depth plays an important role, yet its associated risk premiums are difficult to quantify separately from the risk premiums resulting from credit risk (and in the case of mortgages, the prepayment option). Nonetheless, we show here that the existence of liquidity risk premiums can significantly affect the resulting cost-benefit tradeoff of implementing programs that provide a certain degree of cash-flow insurance.

When the credit enhancement is provided by the Federal Reserve and/or the U.S. Treasury, guaranteeing a minimum cash-flow at a point in time should effectively allow us to trade the cash-flow at a price that is no lower than that of a STRIPS with a face value equal to the guarantee. Therefore, the enhancement brings about a reduction in risk premiums that is larger than the reduction obtained in the sections above. Using $q>0$ to denote the liquidity premium, the price of the cash-flow without the enhancement is now

$$
\begin{aligned}
P(0, t) & =\exp \{-(r+a) \cdot t\} \cdot F(t) \\
& =\exp \{-(r+p+q) \cdot t\} \cdot F(t) .
\end{aligned}
$$

The reduction in the liquidity premium resulting from the enhancement is given by $\lambda \in(0, q]$. Providing a credit enhancement that results in an increase in price $\Delta P(t)$ implies reducing the premium $(p+q)$ by an amount $\beta=(\delta+\lambda)$ that satisfies

$$
\begin{aligned}
\Delta P(t) & =P(0, t)-P_{E}(0, t) \\
& =F(t) \cdot[\exp \{-(r+a-\beta) \cdot t\}-\exp \{-(r+a) \cdot t\}] .
\end{aligned}
$$

In particular, the price today of a cash-flow that has been enhanced with a guarantee of $X(t)$ dollars is given by

$$
\begin{aligned}
P_{E}(0, t) & =(F(t)-X(t)) \cdot \exp \{-(r+p+q) \cdot t\}+X(t) \cdot \exp \{-r \cdot t\} \\
& =F(t) \exp \{-(r+p+q) \cdot t\}+\underbrace{X(t) \cdot \exp \{-r \cdot t\} \cdot[1-\exp \{-(p+q) \cdot t\}]}_{\text {Increase in Price }=\Delta \mathrm{P}} .
\end{aligned}
$$


The price today for the collateral with value $X(t)$ at time $t$ is given by

$$
Y(t)=X(t) \cdot \exp \{-r \cdot t\}
$$

Then the cash-flow price increase and the expected cost of putting up that collateral are given by

$$
\begin{aligned}
& \Delta P(t)=Y(t) \cdot[1-\exp \{-(p+q) \cdot t\}] \\
& E C(t)=Y(t) \cdot[1-\exp \{-p \cdot t\}] .
\end{aligned}
$$

The expression for the expected cost is simply the price of the collateral purchased today, multiplied by the probability that it will be lost.

Since $(p+q)>p$, we see that the change in price is now strictly greater than the expected cost of the intervention,

$$
\triangle P(t)>E C(t)
$$

This last inequality establishes an important difference with the results presented in earlier sections of this appendix, where we did not account for the liquidity effect. Here the central idea is that the change in the asset price that results from insuring a minimum cash-flow depends on the fact that both types of risk premiums drop, while the expected cost only changes with the non-liquidity risk premium. Therefore, providing the insurance is not a zero-sum game, since asset prices increase by more than does the expected cost for the program sponsor. Our criterion for optimality in the allocation of credit guarantees targets the cash flows that are most sensitive to changes in any risk premiums, and should result in increases in asset prices that exceed the implementation cost for the public entity. It is in this sense that our recommended optimality criterion is cost minimizing. For a given expected cost, it consists of the allocation that maximizes the expected price increase. Or put in another way, for a given expected price increase, it minimizes the necessary level of expected cost. 


\section{References}

Balkan, Erol M. 1995. International Bank Lending and Country Risk. New York: Nova Science Publishers.

Bernanke, Ben S., and William Dudley. 2009. Written response to the Congressional Over-sight Panel enquiry of March 20, 2009. Available at http://www.newyorkfed.org/markets/response_040109.pdf (last accessed June 24, 2009).

Cline, William. 1984. International Debt: Systemic Risk and Policy Response. Washington DC: Institute for International Economics.

Cline, William. 1995. International Debt Reexamined. Washington DC: Institute for International Economics.

Emerging Markets Trading Association. 2009). Available at http://www.emta.org/emarkets/brady.html (last accessed June 24, 2009).

Federal Deposit Insurance Corportation. 1997. "The LDC Debt Crisis." In History of the Eighties -Lessons for the Future, 191-210. Available at http://www.fdic.gov/bank/historical/history/191 210.pdf.

Ho, Thomas, S. Y. 1992. "Key Rate Durations: Measures of Interest Rate Risks." The Journal of Fixed Income 2(2): 29-44. Available at http://www.iijournals.com/doi/abs/10.3905/jfi.1992.408049.

Lindert, Peter H.. 1992. "Response the Debt Crisis: What Was Different About the 1980s?" In The International Debt Crisis in Historical Perspective, ed. Barry J. Eichengreen and Peter H. Lindert, 227-275. Cambridge, MA: The MIT Press.

Mauro, Paolo, Nathan Sussman, and Yishay Yafeh. 2006. Emerging Markets and Financial Globalization: Sovereign Bond Spreads in 1870-1913 and Today. New York: Oxford University Press. 


\section{Figures}

\section{Figure 1}

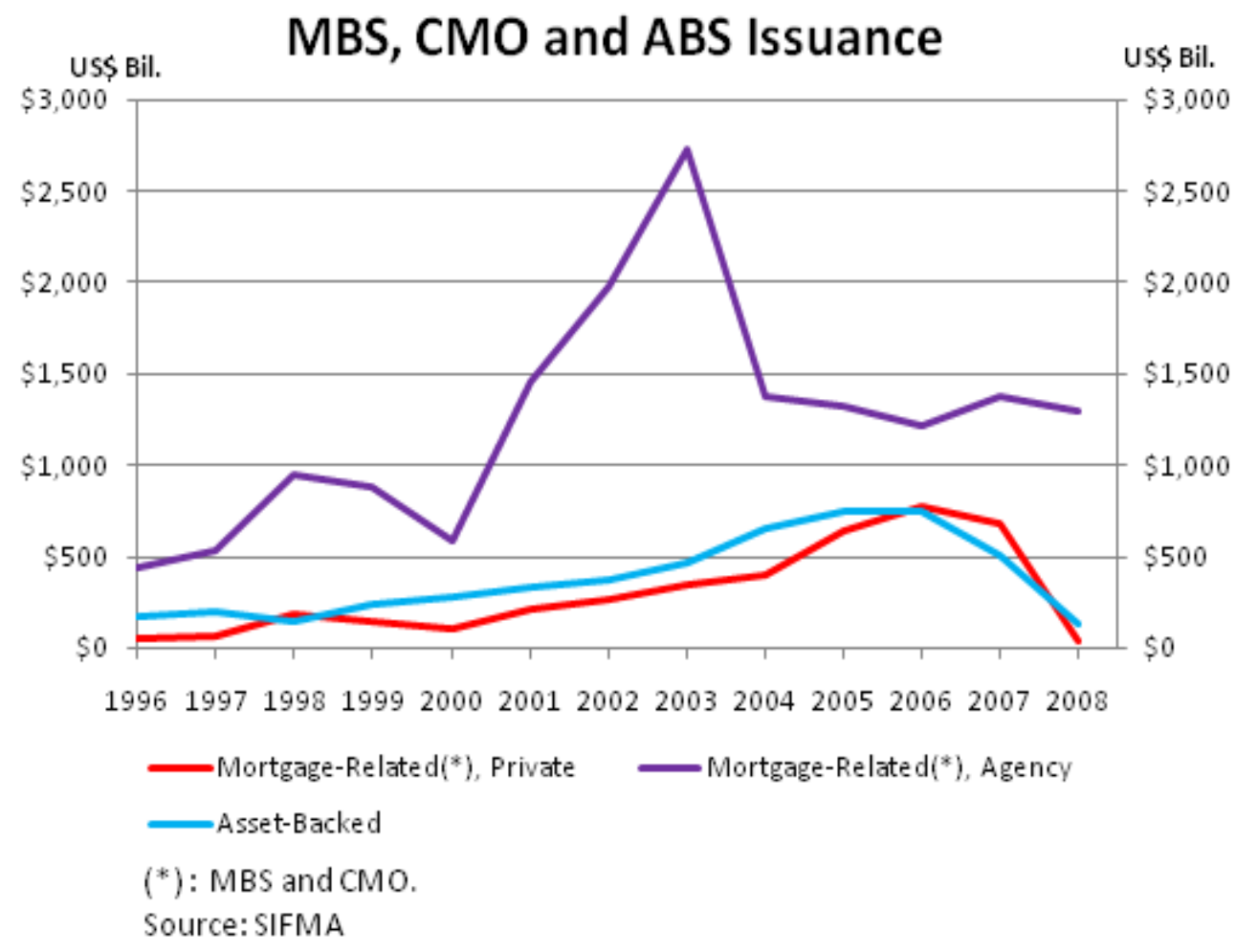

\section{Figure 2}

\section{AAA ABS Spreads $(*)$}

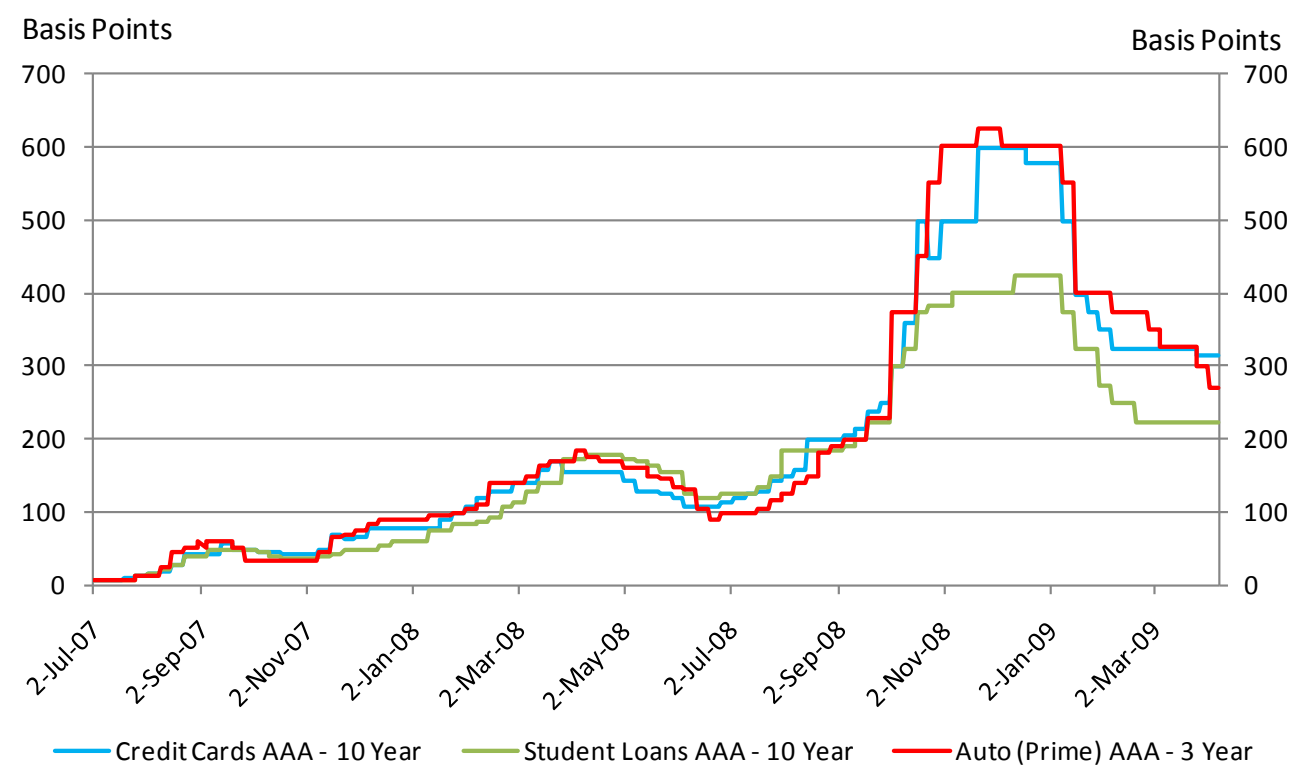

$\left({ }^{*}\right): \quad$ For Credit Cards and Auto (fixed rate) spread is over Swap.

For Student Loans (Libor - FFELP) spread is over 1mo. Libor.

Source: JPMorgan 


\section{Figure 3}

\section{ABX Index, Closing Price}

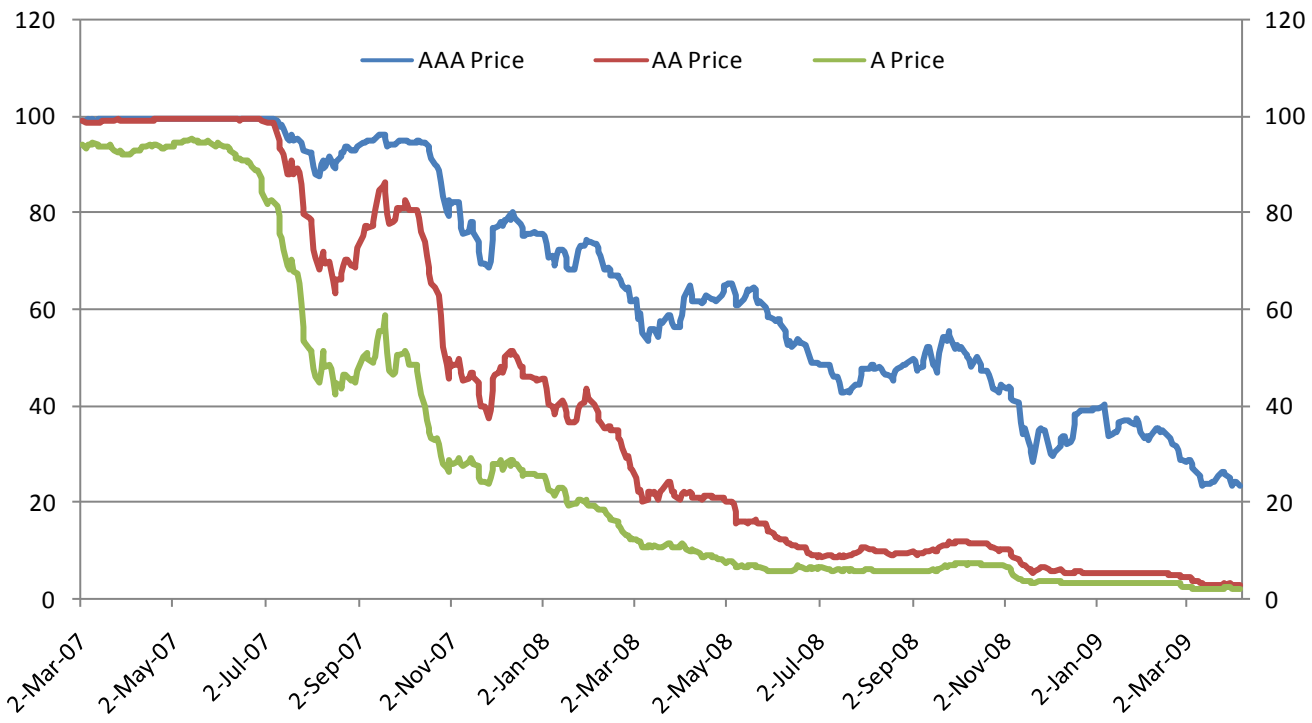

Issue: 2007-1 ABX.HE

Source: JPMorgan

\section{Figure 4}

\section{Mortgage Applications and Refinancing}

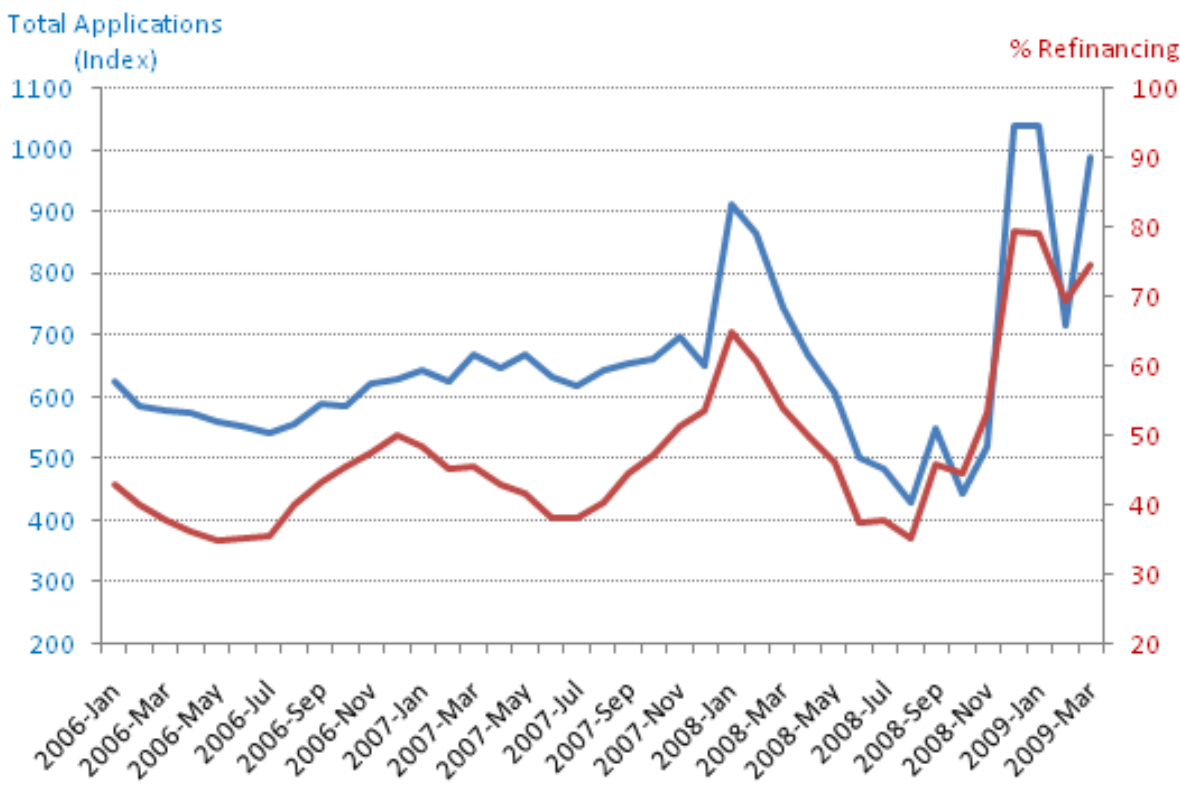

-Index of Mortgage Applications - Left Scale $\left({ }^{*}\right)$

- Percent of Mortgages Granted Used for Refinancing-Right Scale

(*) March $-16-1990=100$

Source: Mortgage Bankers Association / Haver Analytics 


\section{Figure 5}

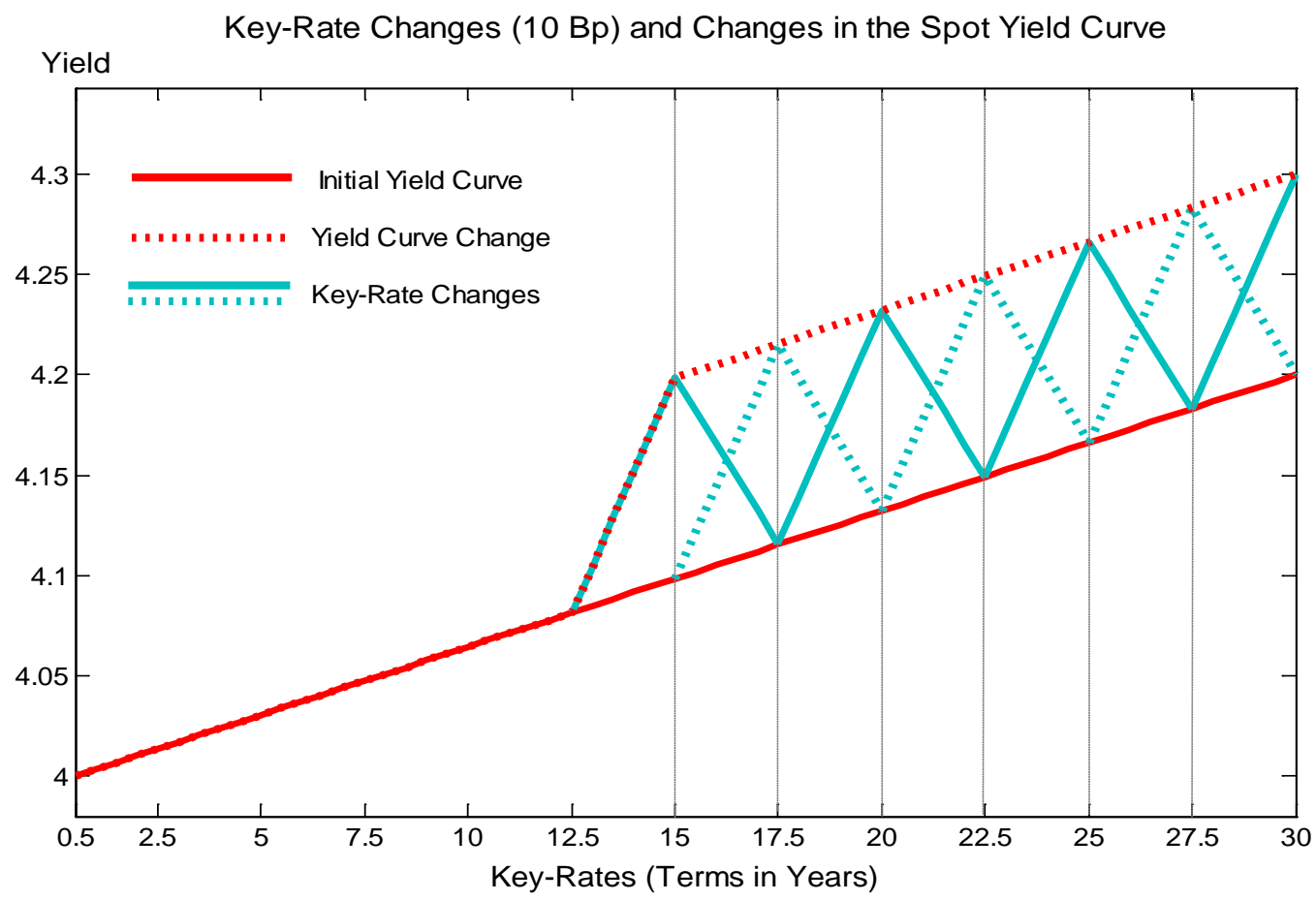

Figure 6

Duration

Key-Rate Durations: Coupon Bonds (Option-Free)

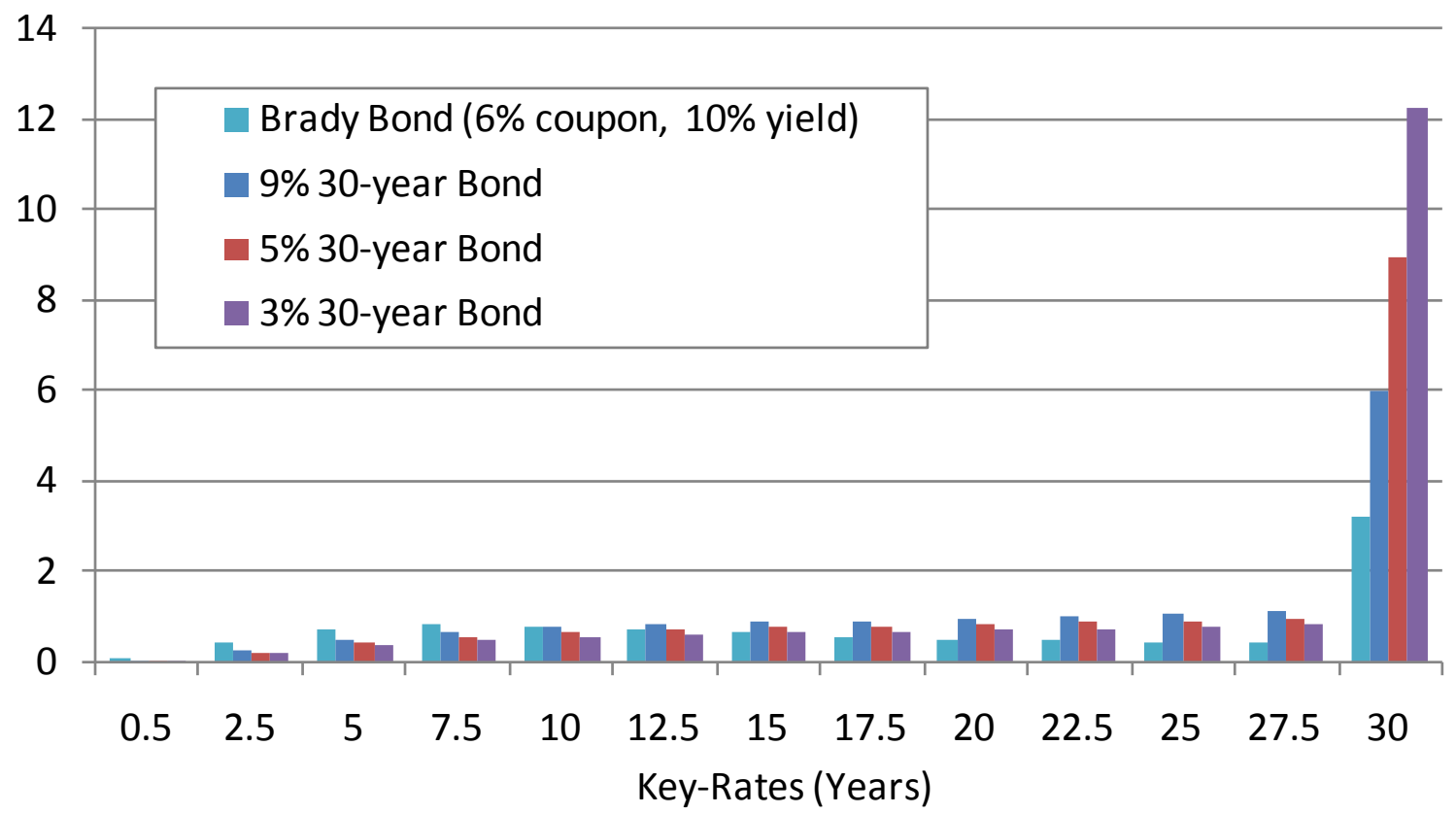

Note: Brady Bond (30-year) with $100 \%$ of original principal, $6 \%$ coupon. Yield is $10 \%$.

The spot rate curve is derived from our benchmark treasury par-coupon yield + parallel shift.

Source: authors' calculations. 
Figure 7

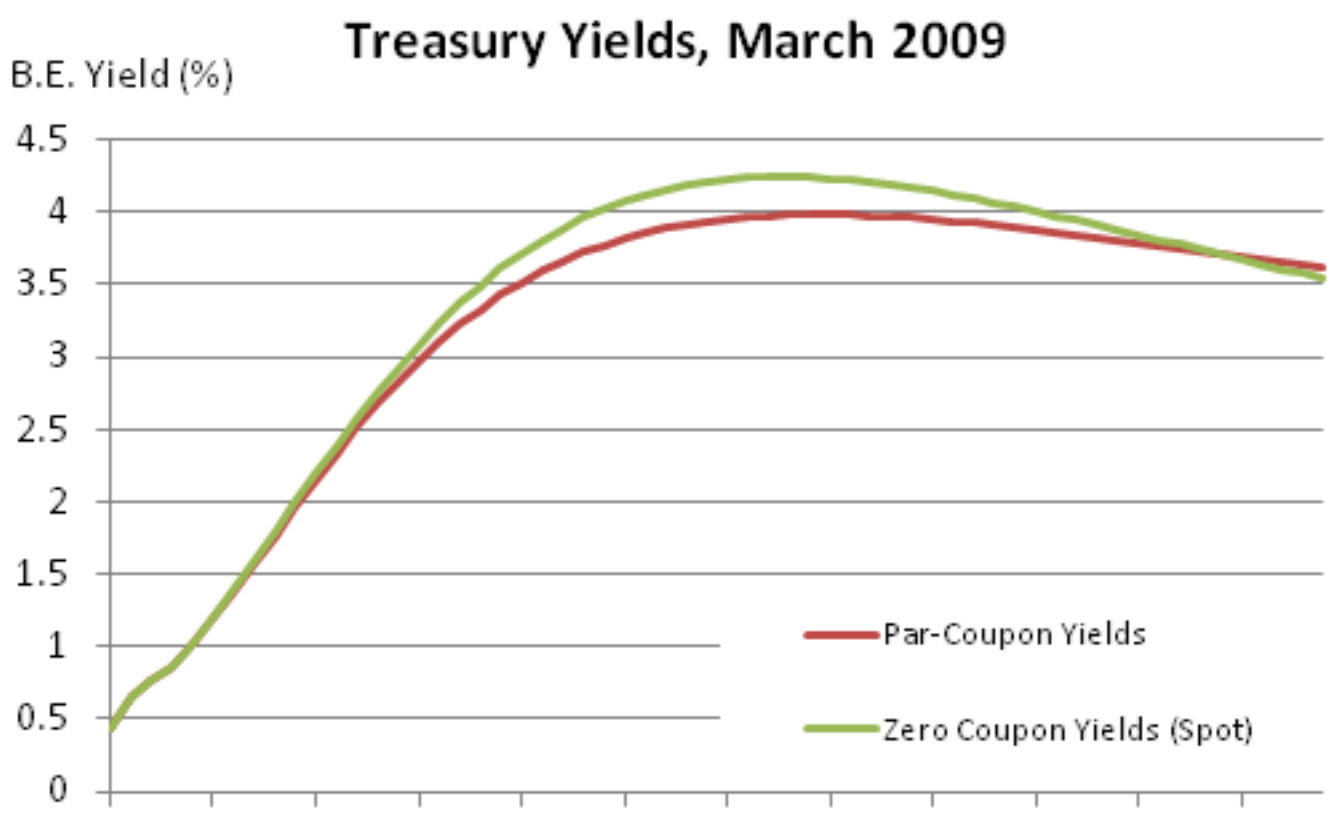

Term

Figure 8

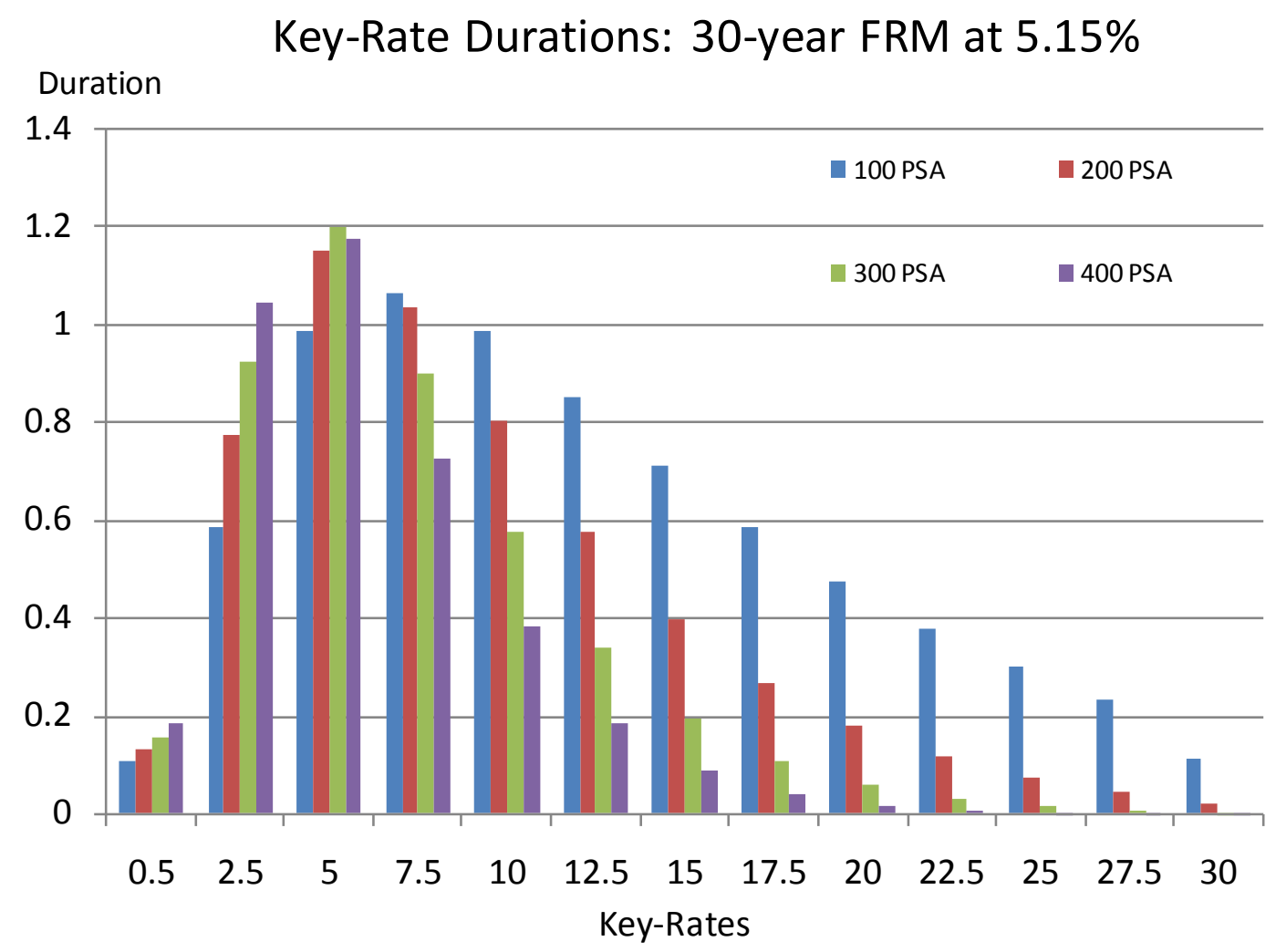


Figure 9

\section{Cumulative Duration: All cash-flows for 400 PSA}

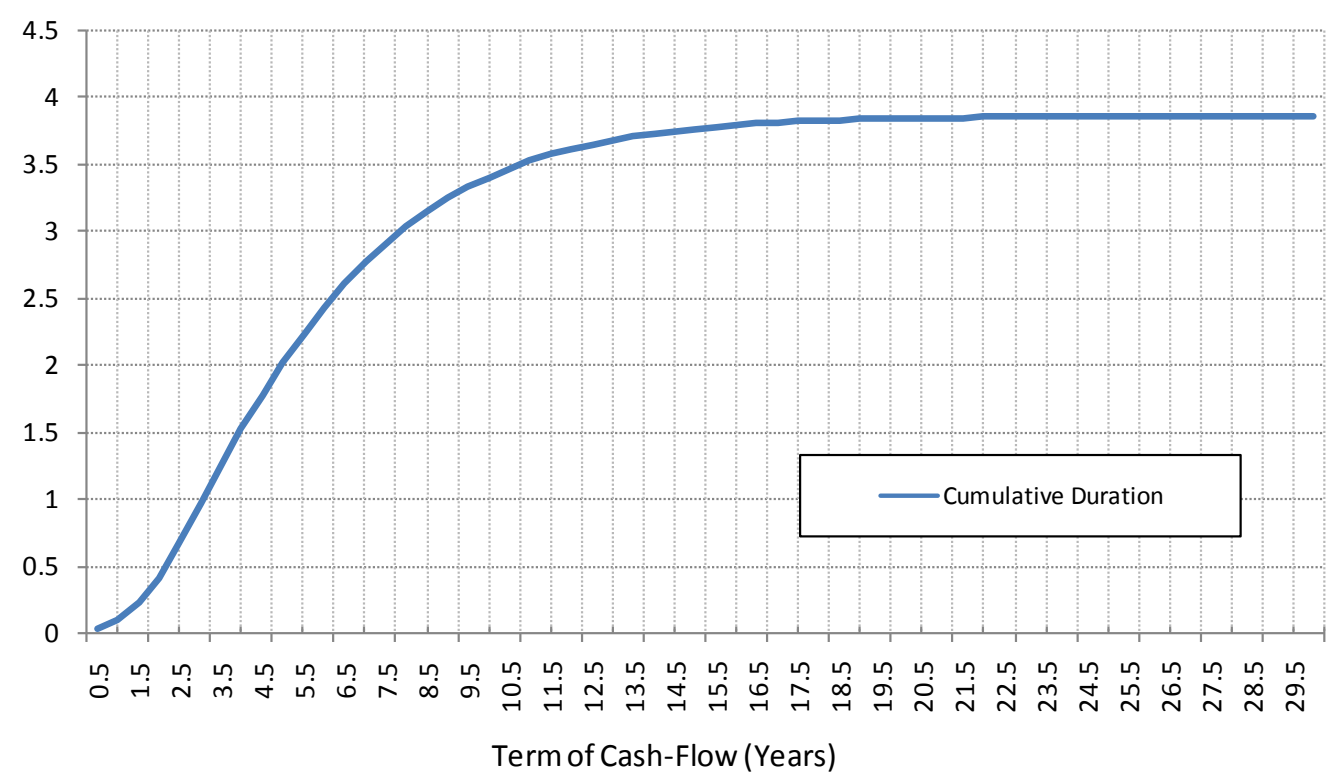

Source: authors' calculations

Figure 10

Insurance Surplus: Bid vs. Ask, Implied Distributions

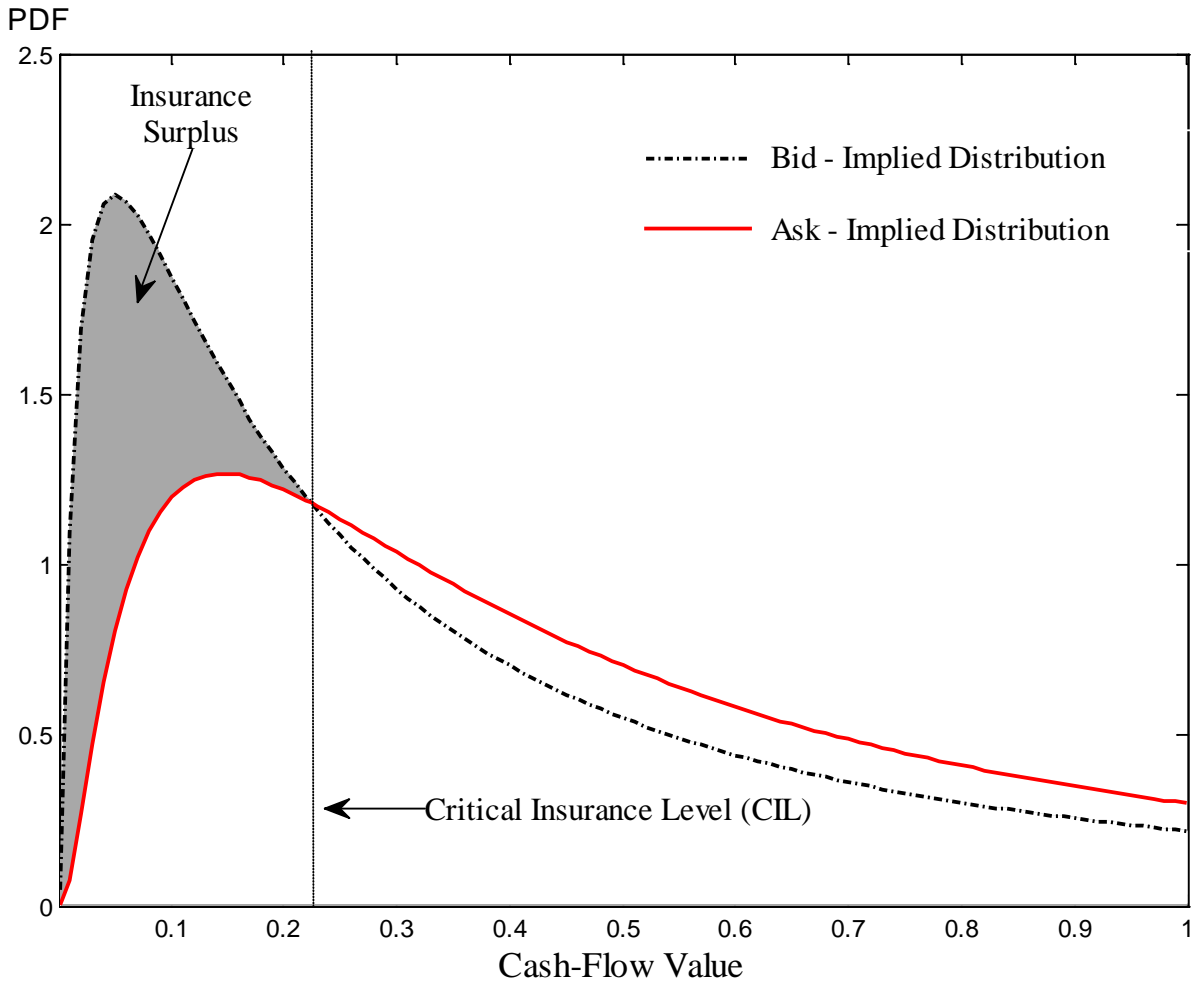


Figure 11

30-Year FR Mortgage Cash Flows with 200 PSA

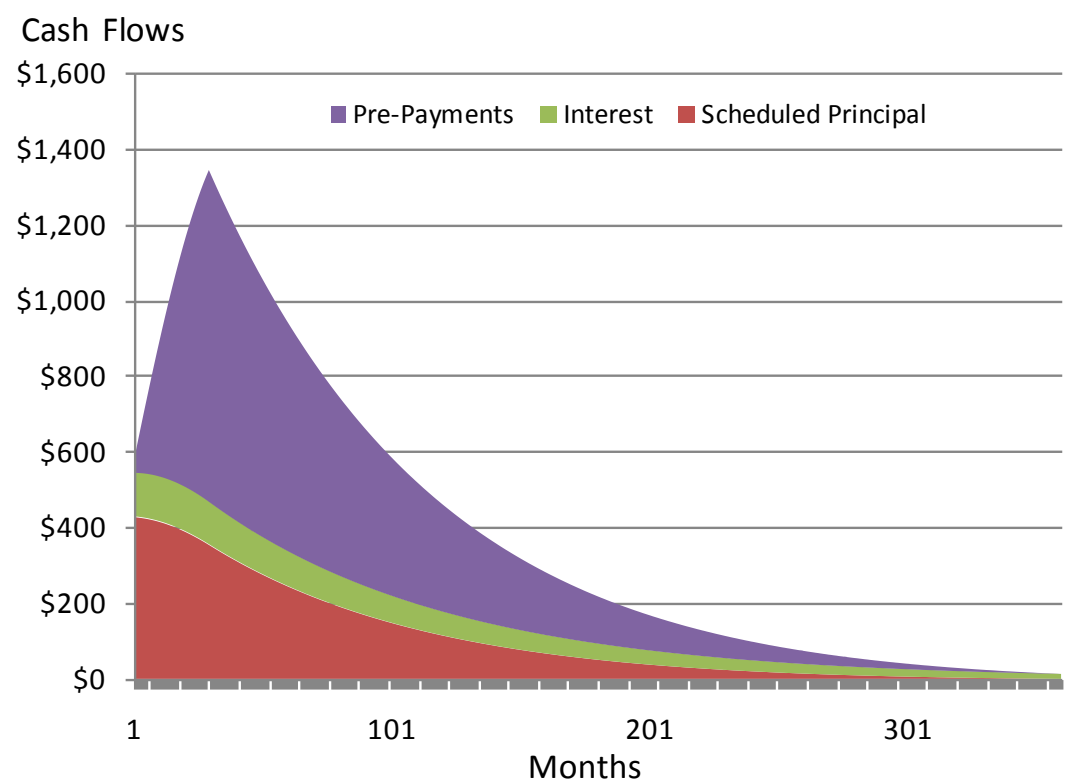

Figure 12

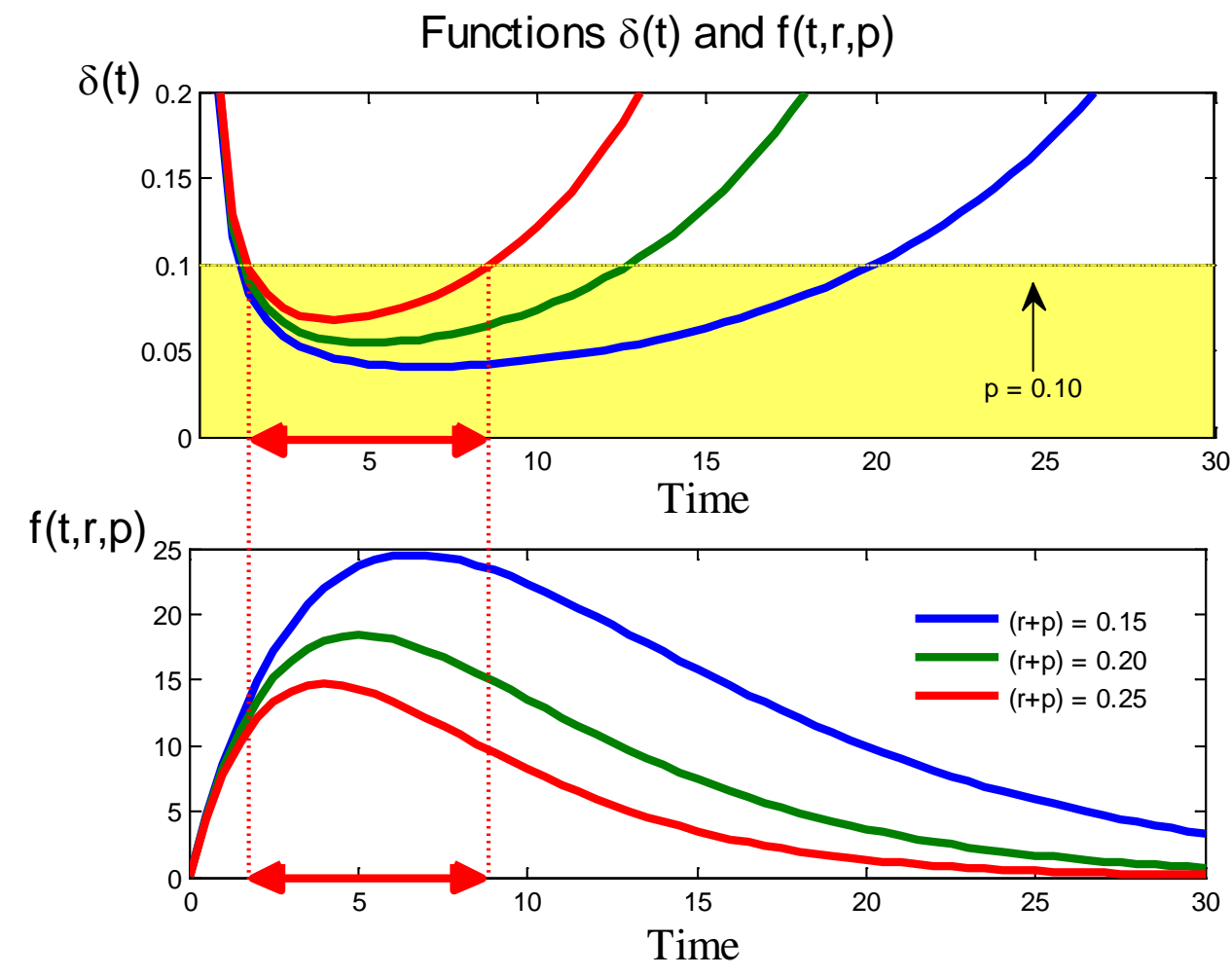

Yellow area shows feasible region where $\delta(\mathrm{t}) \leq \mathrm{p}=0.10$

Red arrows indicate feasible time range for case $(r+p)=0.25$ 